Review

\title{
The Tsaoling landslide triggered by the Chi-Chi earthquake, Taiwan: Insights from a discrete element simulation
}

\author{
Chao-Lung Tang a , Jyr-Ching Hu ${ }^{\text {a,b, },}$, Ming-Lang Lin ${ }^{c}$, Jacques Angelier ${ }^{\text {b,d,e,f }}$, Chia-Yu Lu ${ }^{\text {a,b }}$, \\ Yu-Chang Chan ${ }^{\mathrm{b}, \mathrm{g}}$, Hao-Tsu Chu ${ }^{\mathrm{b}, \mathrm{h}}$ \\ a Department of Geosciences, National Taiwan University, Taipei, Taiwan \\ ${ }^{\mathrm{b}}$ Associated International Laboratory ADEPT, CNRS-NSC, France \\ ${ }^{c}$ Department of Civil Engineering, National Taiwan University, Taipei, Taiwan \\ d Geosciences Azur, Nice University-Pierre-et-Marie Curie University-CNRS, France \\ e Villefranche Oceanological Observatory, Villefranche-sur-Mer, France \\ ${ }^{\mathrm{f}}$ Institut Universitaire de France, France \\ Institute of Earth Sciences, Academia Sinica, Taipei, Taiwan \\ ${ }^{\text {h }}$ Central Geological Survey, MOEA, PO Box 968, Taipei, Taiwan
}

\section{A R T I C L E I N F O}

\section{Article history:}

Received 27 May 2008

Received in revised form 9 February 2009

Accepted 18 February 2009

Available online 9 March 2009

\section{Keywords:}

Tsaoling landslide

Chi-Chi earthquake

Discrete element simulation

\begin{abstract}
A B S T R A C T
In the village of Tsaoling (in Yunlin County, Taiwan), a major landslide was triggered by the Chi-Chi earthquake in 1999 with more than $125 \times 10^{6} \mathrm{~m}^{3}$ of rock displaced. The kinematic behaviour of this landslide is simulated using a 2D discrete element model (PFC2D code). Our numerical model is composed of discs bonded together. The initial boundary conditions are applied along the ball-wall contacts by using derived velocities integrated from the strong motion data with a duration of $160 \mathrm{~s}$ including the peak acceleration near Tsaoling. The constraints are mainly issued from the final geometry of the landslide including its capacity to cross the river valley and reach a significant elevation on the opposite mountain flank. They also result from a variety of geological and hydrological observations, including the local levels of material disruption and the location of survivors. Our modelling thus indicates that a low-friction coefficient (about 0.15) and a medium strength are required to account for the actual landslide characteristics. A self-lubrication mechanism probably accounts for the low residual friction. Our model also suggests that the maximum velocity of sliding reached $50 \mathrm{~m} / \mathrm{s}$, a result that cannot be checked in the absence of actual measurements. In addition to friction, the strength of sliding block is of special importance because it controlled the possibility for the upper layer fragments to roll and get buried, and hence the probability of survival.
\end{abstract}

(c) 2009 Elsevier B.V. All rights reserved.

\section{Contents}

1. Introduction .........? 2

1.1. The 1999 Tsaoling landslide . . . . . . . . . . . . . . . . . . . . . . . . . . . . . . . . 2

1.2. Deformation and friction in landslides . . . . . . . . . . . . . . . . . . . . . . . . . . 2

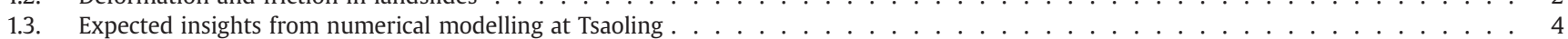

2. Geological framework . . . . . . . . . . . . . . . . . . . . . . . . . . . . . 5

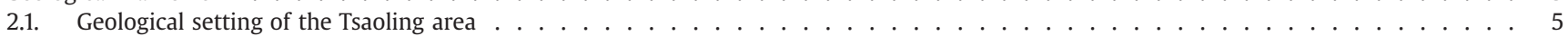

2.2. Historical landslides at Tsaoling . . . . . . . . . . . . . . . . . . . . . . . . . . 5

2.3. The Chi-Chi earthquake and the 1999 Tsaoling landslide . . . . . . . . . . . . . . . . . . . . . . . . . . 5

2.4. The role of groundwater . . . . . . . . . . . . . . . . . . . . . . . . . . . . .

3. The Newmark displacement method and 2D Distinct Element modelling . . . . . . . . . . . . . . . . . . . . . . . . . 6

3.1. Principle of the Newmark displacement method . . . . . . . . . . . . . . . . . . . . . . . . . . . . . . . . . 6

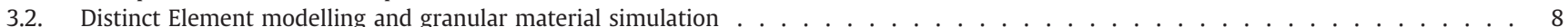

3.2.1. Numerical damping . . . . . . . . . . . . . . . . . . . . . . . . . . . . . . . . . . . 8

3.2.2. Microproperties. . . . . . . . . . . . . . . . . . . . . . . . . . . . . . 8

3.2.3. Biaxial test. . . . . . . . . . . . . . . . . . . . . . . . . . . . . . . . . . . . . . . . .

\footnotetext{
* Corresponding author: Department of Geosciences, National Taiwan University, Taiwan. Tel.: +886 233662943 ; fax: +886 223636095.

E-mail address: jchu@ntu.edu.tw (J.-C. Hu).
} 
4. Results of numerical experiments for the Tsaoling landslide . . . . . . . . . . . . . . . . . . . .

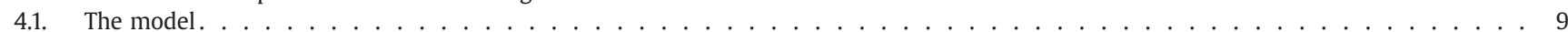

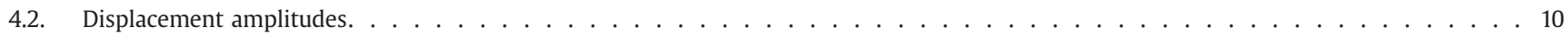

4.3. Constraints on friction coefficients . . . . . . . . . . . . . . . . . . . . . . . . . . . 12

4.4. Constraints on bond strength and cohesion . . . . . . . . . . . . . . . . . . . . . . . . . 13

4.5. Evolution of fragmentation during the landslide event . . . . . . . . . . . . . . . . . . . . . . . . . . 13

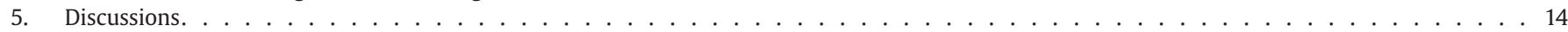

5.1. Slope stability at Tsaoling during the Chi-Chi earthquake . . . . . . . . . . . . . . . . . . . . . . . . . 15

5.2. Lubrication mechanisms . . . . . . . . . . . . . . . . . . . . . . . . . . . 15

5.3. Runout distance . . . . . . . . . . . . . . . . . . . . . . . . . . . . . . . . . . . 16

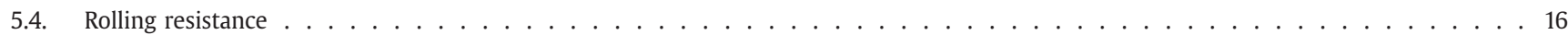

5.5. Possibility of survival following the Tsaoling landslide . . . . . . . . . . . . . . . . . . . . . . . . . . . . 17

5.6. The Tsaoling landslide as a case example for future studies. . . . . . . . . . . . . . . . . . . . . . . . . . . . 17

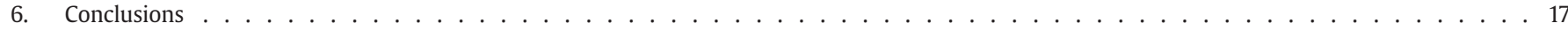

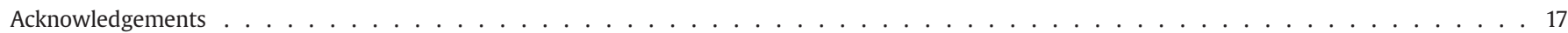

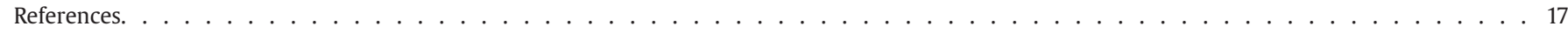

\section{Introduction}

Earthquake shaking is considered to be one of the main agents of the generation of a landslide with the largest earthquakes capable of triggering thousands of landslides throughout areas of more than $100,000 \mathrm{~km}^{2}$ (Keefer, 1984, 2000; Keefer and Larsen, 2007). In Taiwan, landslide hazard reaches high levels in the mountainous part of the island where argillaceous slate lithology, earthquakes, typhoons and heavy rainfall facilitate to favour gravitational sliding (Hsu and Leung, 1977; Hung, 2000). Thus the basic physics governing the initiation of landslides such as material strength, gravitational stress, external forces due to seismic shaking and pore-fluid pressure have been well studied for decades (e.g., Crosta, 1998; Legros, 2002; Crosta et al., 2003; Keefer and Larsen, 2007).

\subsection{The 1999 Tsaoling landslide}

Numerous landslides have been observed in the mountain terrain adjacent to the epicentral area of the Chi-Chi earthquake which occurred on September 21st, 1999 (CGS, 1999). Based on the study of SPOT images, Liao (2000) pointed out that the Chi-Chi earthquake had triggered 9272 landslides and the total area of the landslides is $128 \mathrm{~km}^{2}$.

Among the many catastrophic landslides of West-Central Taiwan where the disastrous Chi-Chi earthquake occurred in 1999 (Fig. 1a), the most impressive is located in Tsaoling on the northern side of the Chingshui River valley (Fig. 1b). The shape of the detachment and accumulation areas of the landslide is shown in Fig. 1c. At least five major dip slope failures occurred at Tsaoling during the 19th and 20th centuries (Hung, 2000; Hung et al., 2002) with the last triggered by the 1999 Chi-Chi Earthquake (Table 1). The estimated volume of the Tsaoling landslide is about $125 \times 10^{6} \mathrm{~m}^{3}$ (Hung et al., 2002). The volume of fill is about $150 \times 10^{6} \mathrm{~m}^{3}$, based on integration of aerial photogrammetry and digital terrain model analyses within the frame of a GIS (Geographic Information System) with 10 m pixel size resolution (Liao, 2000). As Fig. 2 shows, about $20 \%$ of the sliding mass accumulated in the Chingshui River valley (Fig. 2), creating a 5km-long dam and a lake (Hung et al., 2002) which was deeply incised by the river erosion over the next few years (Chen et al., $2005,2006)$. Moreover, significant portions of this mass "flied" over the valley and accumulated in the lower portion of the opposite mountain flank.

\subsection{Deformation and friction in landslides}

Although strong and pervasive disruption occurred inside the sliding terrain, as can be observed in the landslide mass, the moving components of many large landslides show a remarkable tendency to remain in a more or less unchanged, sequential order and shows that the main landslide mass undergoes severe fracturing and disruption but relatively limited deformation during the event. Observations in sedimentary terrain often show that the original order of the strata is preserved in the landslide (Johnson, 1979). This suggests that whereas the rock masses experience sufficient stress to induce dense fracturing of rock layers, stresses are applied during a very short time span, thus inhibiting large internal deformation and significant rearrangement of the deposit. As a consequence, most of the deformation often remains confined to narrow basal regions of landslide mass (Cleary and Campbell, 1993) where simple shear prevails.

In addition, for massive catastrophic long runout landslides, the apparent friction coefficient, defined as the ratio between the total vertical and horizontal displacements as proposed by Heim (1932), is many times smaller than the friction coefficient indicated by standard tests of material mechanical properties. For the largest landslides this parameter may fall below 0.1. The largest landslide on planet Mars, estimated to have a volume of $17,880 \mathrm{~km}^{3}$, moved with an apparent friction coefficient of 0.06 (Lucchitta, 1979; McEwen, 1989). The dynamics of Valles Marineris are controversial: either the landslides are interpreted as dry rock avalanches or as gigantic debris flow. Lucchitta (1978) have proposed that the Valles Marineris landslide were probably gigantic wet debris flows. These fluidization mechanisms are also suggested based on the morphology and geometry of Valles Marineris landslides (Quantin et al., 2004) and a dynamic finite-difference model (Harrison and Grimm, 2003). In comparison with the power-law relationship between the volume and run-out distance of landslide on Earth and those in Valles Marineris, Soukhovitskaya and Manga (2006) argued that water did not play a significant role in the dynamics of martian landslides. The exponent of the power-law for martian landslides is similar to that for dry landslides and volcanic flows on Earth. Furthermore, the apparent friction decreases as the volume of slide increases (Heim, 1932).

Many interpretations have been proposed to explain the low apparent friction of long runout landslides. For instance, it has been considered that the basal area of the slide is lubricated by a layer of trapped air (Shreve, 1968). The material may be liquified by a flow of air through its mass (Kent, 1966). A similar concept was also proposed to explain the disastrous Vaiont landslide of October 9th, 1963, in north Italy (Habib, 1967, 1975). The low apparent friction resulted from partial melting of part of the constituent minerals that resulted from the large energy dissipation of the slide (Erismann, 1979; Voight and Faust, 1982). In the deposits of the Köfels landslide, melted rock (frictionite) was observed (Eriscmann, 1986). Melosh $(1979,1986)$ has proposed the idea of 'acoustic fluidization', meaning that the low friction is explained by acoustic energy stored in the constituent rocks, forcing intermittent contact and low-friction slip between the constituent rocks. Hsü $(1975,1978)$ proposed that the apparently excess travel distance of many sturzstroms might be related to a reduction of frictional resistance of colliding blocks dispersed in a dust 
(a)

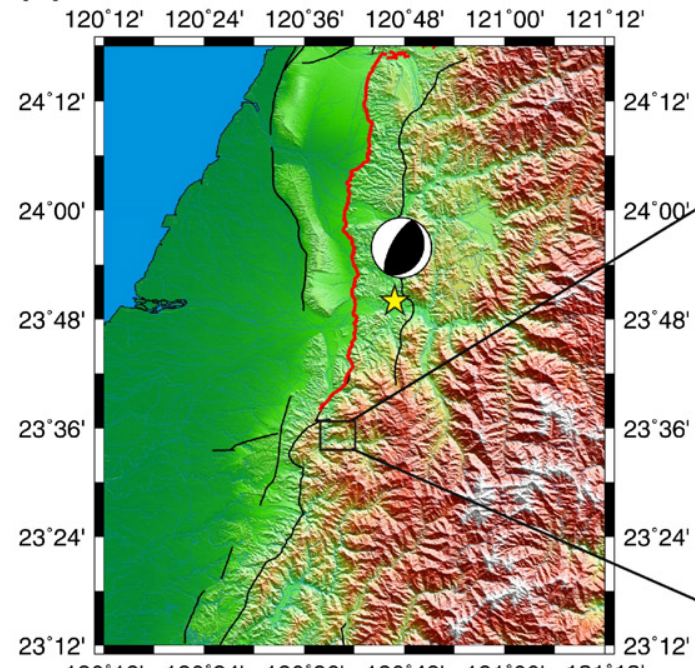

$120^{\circ} 12^{\prime} \quad 120^{\circ} 24^{\prime} \quad 120^{\circ} 36^{\prime} \quad 120^{\circ} 48^{\prime} \quad 121^{\circ} 00^{\prime} \quad 121^{\circ} 12^{\prime}$

(c)

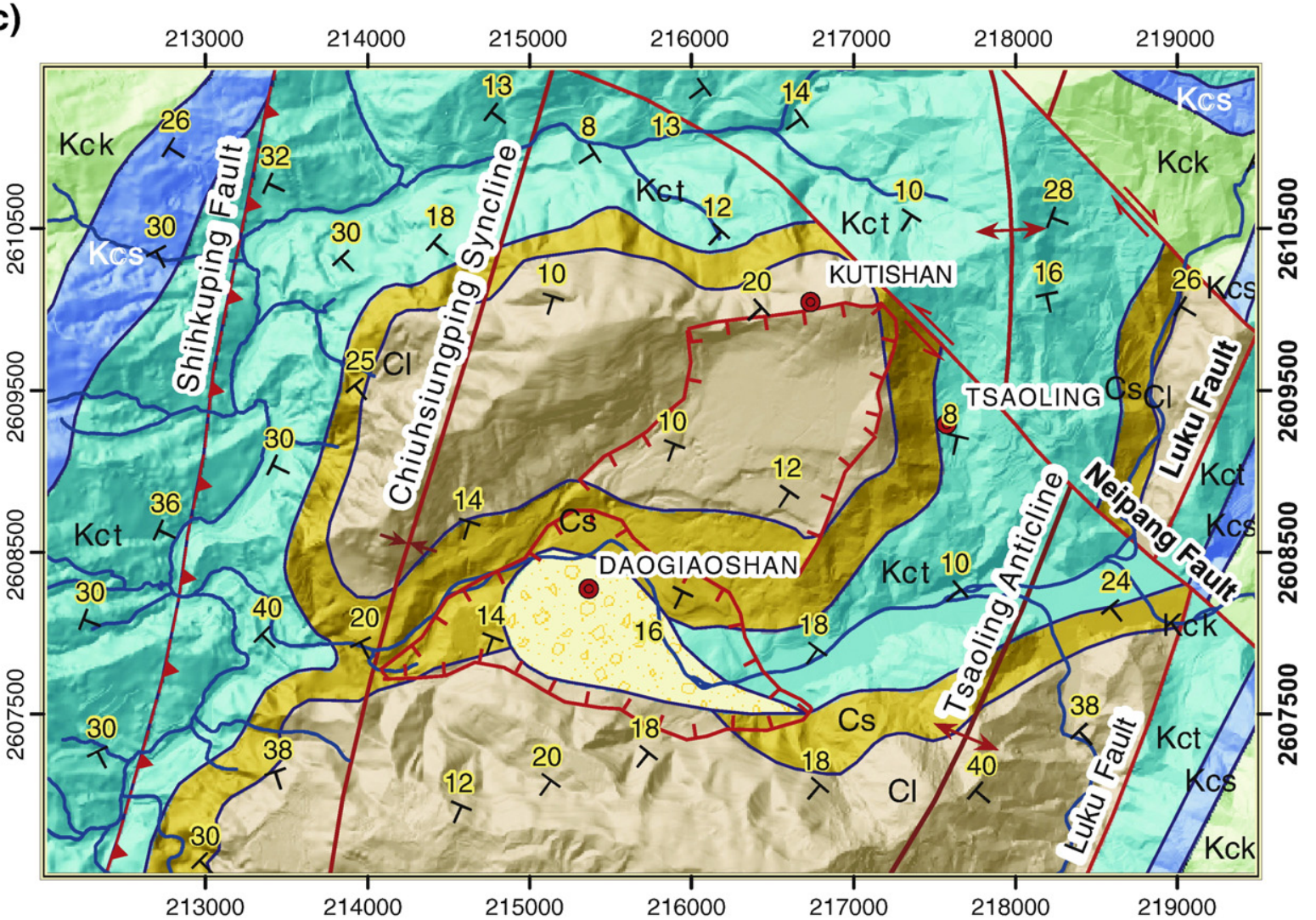

Cl Interbeds of sandstone, mudstone and shale (Chaolan Formation)

Cs

Shale with intercalated sandstole (Chinshui Shale)

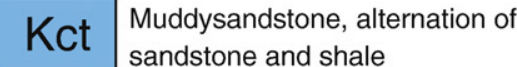
KCS Shale with intercalated sandstone

KCK Muddy sandstone

(b)

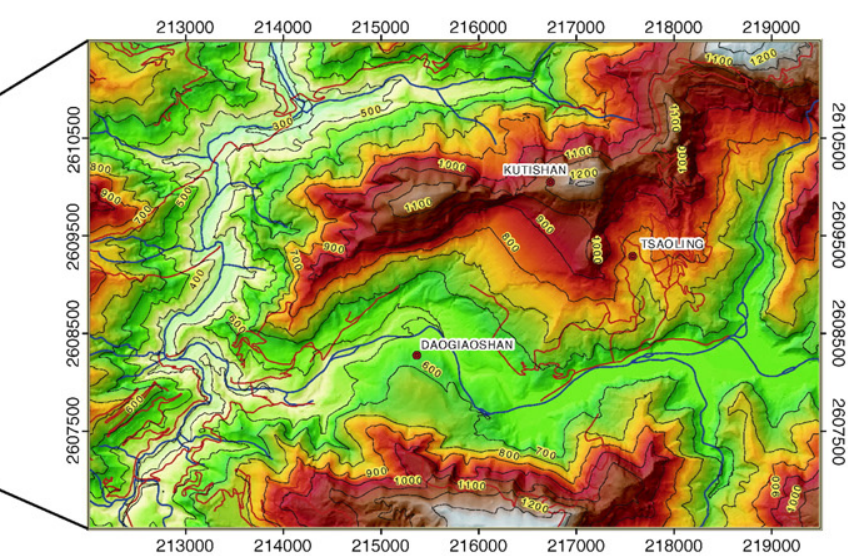
. 
Table 1

Summary of historical landslides in the Tsaoling area, Taiwan, 1862-1999.

\begin{tabular}{|c|c|c|}
\hline Date & Trigger & Note \\
\hline June 6,1862 & Earthquake $(M=7.0)$ & $\begin{array}{l}\text { Landslide; formation of a landslide } \\
\text { dam. }\end{array}$ \\
\hline $\begin{array}{l}\text { December 17, } \\
1941\end{array}$ & Earthquake $(M=7.1)$ & $\begin{array}{l}\text { Landslide volume: } 84 \text { million } \mathrm{m}^{3} \text {. } \\
\text { Landslide dam ( } 70-200 \mathrm{~m} \text { in } \\
\text { height) was formed. A dammed } \\
\text { lake contained } 12.8 \mathrm{M} \mathrm{m}^{3} \text { of water. }\end{array}$ \\
\hline August 10,1942 & $\begin{array}{l}\text { Rainfall: } 3 \text { day cumulative } \\
\text { precipitation of } 770 \mathrm{~mm}\end{array}$ & $\begin{array}{l}\text { Landslide volume: } 100 \text { million } \mathrm{m}^{3} \text {. } \\
\text { Landslide dam ( } 140-217 \mathrm{~m} \text { in } \\
\text { height) formed. A larger dammed } \\
\text { lake containing } 157 \text { million } \mathrm{m}^{3} \text { of } \\
\text { water, which failed on May } 18,1951 \text {, } \\
\text { killing } 147 \text { people. }\end{array}$ \\
\hline August 15, 1979 & $\begin{array}{l}\text { Rainfall: } 2 \text { day cumulative } \\
\text { precipitation of } 327 \mathrm{~mm}\end{array}$ & $\begin{array}{l}\text { Landslide volume: } 26 \text { million } \mathrm{m}^{3} \text {. A } \\
\text { landslide dam ( } 90 \mathrm{~m} \text { in height) formed } \\
\text { and a dammed lake containing } \\
40 \text { million } \mathrm{m}^{3} \text { of water. }\end{array}$ \\
\hline $\begin{array}{l}\text { September 21, } \\
1999\end{array}$ & $\begin{array}{l}\text { Chi-Chi Earthquake } \\
\left(M_{\mathrm{L}}=7.3\right)\end{array}$ & $\begin{array}{l}\text { Landslide volume: } 125 \text { million } \mathrm{m}^{3} \text {. A } \\
\text { debris dam formed with a height of } \\
50 \mathrm{~m} \text { at upstream and } 150 \mathrm{~m} \text { at } \\
\text { downstream. Estimated storage } \\
\text { capacity larger than } 46 \text { million } \mathrm{m}^{3} \text {. }\end{array}$ \\
\hline
\end{tabular}

suspension. Based on simple particle dynamics, Campbell (1989, 1990) suggested that the reduction of friction without the intervention of external processes such as air layers is linked with lubrication mechanisms, the observed low friction being explained in terms of granular flow over a dilute layer of highly agitated particles. The high energy concentration in the zone located near the sliding surface induced self-lubrication transformed rock into fragmented sheared material by fundamental tribological mechanisms (Campbell, 1989, 1990; Cleary and Campbell, 1993; Campbell et al., 1995).

\subsection{Expected insights from numerical modelling at Tsaoling}

The assessment of landslide hazard requires the knowledge of the landslide characteristics and runout mechanics. To better simulate the evolution of the mechanism of failure within the moving mass and the possible causes of the runout, both empirical and numerical models were preformed. In general, empirical models (e.g., Legros, 2002) lack robustness due to the comprehensive description of complex geological and geotechnical conditions of large flow-like landslide. However, the adoption of the continuum method demonstrates the advantage of representation of complex geometry of the rock avalanche (Crosta et al., 2006). For numerical modelling, the finite difference schemes in Eulerian framework with a fixed reference grid are disadvantageous in describing highly unsteady motion (Sousa and Voight, 1991). In addition, the finite element modelling is presented in literature by adopting the proper constitutive law for the overall rock mass and the calibration of parameters (e.g., Forlati et al., 2001; Quecedo et al., 2004; Zheng et al., 2005). In general, for overcoming the excessive distortion of the computational grids, the Lagrangian finite element method (LFEM) was formulated (Chen and Lee, 2000, 2003) and a combined EulerianLagrangian method was carried out (Crosta et al., 2003, 2006) to reproduce the dynamic runout process caused by landslide. The complex kinematics of the flowing mass depends on the morphological and geological characteristics of the slope, as well as the rheology of surface material and the triggering process. The refined numerical solutions and a Coulomb-like behaviour had been successfully carried out for a threedimensional granular mass flow (Denlinger and Iverson, 2001; Iverson and Denlinger, 2001; Iverson and Vallance, 2001). Landslides often involve heterogeneous granular materials such as rocks and debris which may fall, topple or slide (Cruden and Varnes, 1996). Thus, the numerical modelling based on the discrete element method is a powerful tool for modelling rock slope susceptibility to earthquakes. In this respect, the explicit solution in the time domain used by this method is ideal to study the time propagation of a stress wave or a ground vibration. Many research studies on rock mechanics, rate-and-state friction behaviour and landslides have been performed with some success by using numerical applications of the discrete element method (Campbell et al., 1995; McDowell and Harireche, 2002; Cheng et al., 2003; Potyondy and Cundall, 2004; Taboada et al., 2005, 2006). Because it takes mechanical discontinuities in explicit account, this technique is preferable to modelling approaches in terms of continuum mechanics which poorly account for the actual mechanical behaviour of disrupted landslide masses.

In the case of the Tsaoling landslide triggered by the Chi-Chi earthquake, several field investigations have been done for landslide mapping and the triggering mechanism (Hung, 2000; Hung et al., 2002; Chigira et al., 2003; Chen et al., 2003). Because of its large size and relative structural simplicity, the Tsaoling landslide provides a

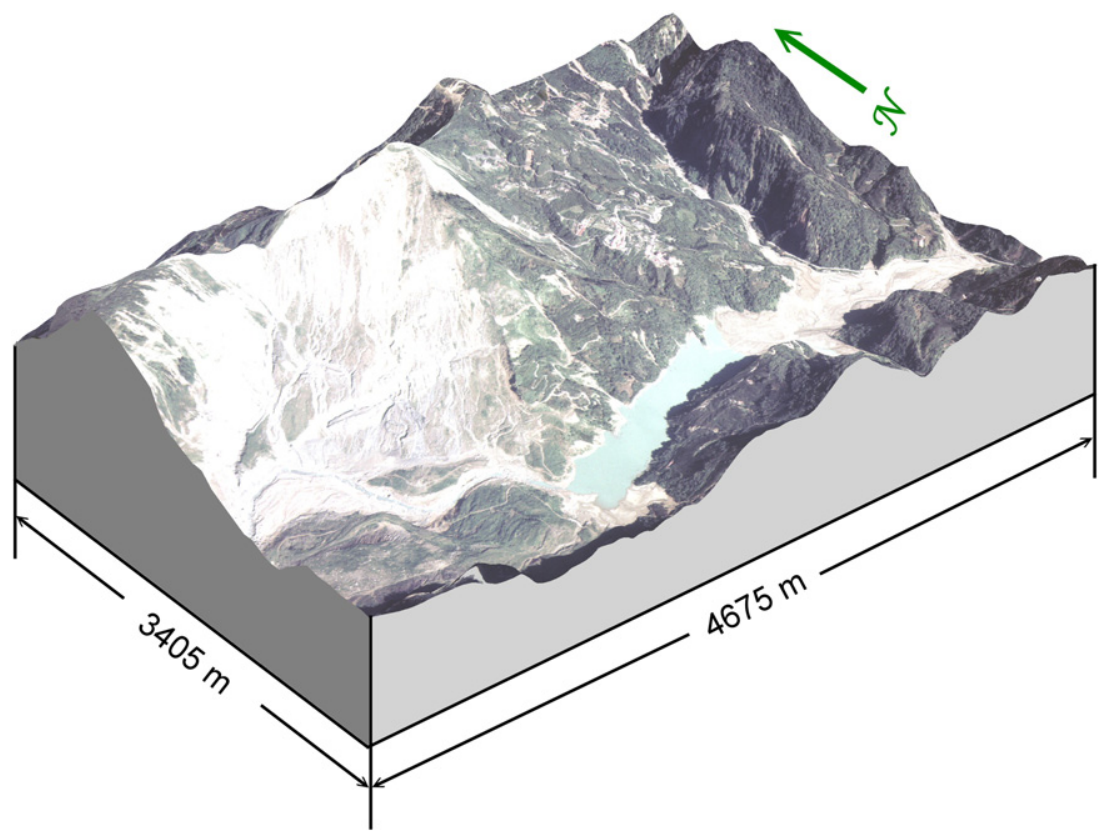

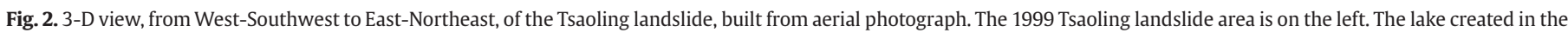
Chuinshui River because of the natural dam arising from the 1999 Tsaoling landslide. 
case example for landslide studies. However, the kinematical process of the Tsaoling landslide event still remains poorly understood. Thus, the main goal of this paper is to address the kinematical mechanism of the Tsaoling landslide using a 2D discrete element based on the use of granular material. Because landslides often involve heterogeneous granular materials such as rocks and debris, the discrete element is appropriate for the analysis of the sliding process. In addition, the complex kinematics of the sliding mass depends on the morphological and geological characteristics of the slope, the rheology of sliding materials and the triggering processes. The mechanic properties such as the frictional behaviour of sliding surface and the strength of sliding granular materials consequently deserve attention in order to characterise the complex kinematics and triggering process of a large landslide such as the Tsaoling landslide.

In this paper, we focus on analysing the kinematics and mechanical behaviour of the Tsaoling landslide as constrained by the geometry and structure of the sliding mass before and after the event. Other geological observations about lithology, structure and hydrology provide further constraints, as well as the initial reports about the 1999 disastrous landslide. We especially seek to model the relationships between the overall mechanical parameters of the landslide such as the basal friction and internal cohesion and the landslide displacement. This mechanical analysis raises additional inferences regarding the velocity of the sliding process, which are not constrained by first-hand data and the internal deformation of the landslide which can be checked from field observation and topographic data.

\section{Geological framework}

The village of Tsaoling is located in the middle part of the valley through which runs the Chingshui River (Chingshuihsi), a tributary of the Choshuihsi, the largest river of Taiwan. The difference in elevation between the river and the surrounding summits reaches about $750 \mathrm{~m}$, for an average valley width of $2 \mathrm{~km}$ (Fig. 1b). The average slope of the valley flanks is commonly as steep as $37.5 \%$.

\subsection{Geological setting of the Tsaoling area}

The Tsaoling area belongs to the western Foothills of Taiwan, about $10 \mathrm{~km}$ east of the front thrusts of the mountain belt (Fig. 1a); it is affected by major, west-vergent thrust faults. The bedrock of the Tsaoling area is Pliocene in age and belongs to the upper Chinshui Shale and the lower Cholan Formation (Fig. 1c). The Chinshui Shale crops out only on the edge of the landslide area where it is overlain by the Cholan Formation. The main detachment surface of the 1999 Tsaoling landslide developed parallel to bedding in the lower Cholan Formation as shown by the cross-section of Fig. 3.
From a lithological point of view, the Chinshui Shale consists mainly of massive mudstone and shale frequently intercalated with a fine to very fine-grained sandstone layer. The Cholan Formation, which conformably rests on the Chinshui Shale, mainly consists of greenish-gray fine-grained sandstone with variable amounts of shale. The Tsaoling area is located in a large monocline dipping towards the south-southwest, The stratal dips toward the SSW are similar on both sides of the Chingshui River valley, so that landslide occurrence is facilitated on the northern side of the river (right bank side) where the mountain flank dips steeper than, and in the same direction as, the layers. Conversely, large landslides do not occur on the southern side of the river where the mountain flank and the layers dip in opposite directions. The layers uniformly dip $14^{\circ} \mathrm{SW}$ with a $\mathrm{N} 40^{\circ} \mathrm{W}$ strike in the Tsaoling landslide area. The monocline area where the landslide could develop is approximately $3 \mathrm{~km}$ wide from West to East between the two major folds (Chiuhsiungping syncline and Tsaoling anticline). Because of this structural pattern at Tsaoling, the relatively constant shallow stratal dip towards the Chingshui River combined with the steeper, south-facing mountain slope obviously facilitates a landslide phenomenon in terms of geological structure.

\subsection{Historical landslides at Tsaoling}

The occurrence of successive landslides and related destruction in the Tsaoling area has been documented for the past 140 years (Hsu and Leung, 1977; the Taiwan Provincial Water Conservancy Bureau, 1979; Huang et al., 1983; Hung, 2000; Hung et al., 2002; Chigira et al., 2003). A summary is presented in Table 1 . Historical catastrophic dip slope failures have occurred several times, triggered by heavy rainfalls (1942 and 1979) or destructive earthquakes (1862 and 1999) (Hung, 2000; Hung et al., 2002). Ruptures of natural dams created by landslides occurred in 1898 , 1951 and 1979 (Hung, 2000). The first recorded Tsaoling landslide was triggered by a major earthquake in 1862 , with estimated magnitude $M=7.0$ (Tsai, 1985), and the corresponding natural dam failed in 1898 . Another major earthquake resulted in the second landslide at the same location in 1941, and a heavy rainfall led to the reactivation of a landslide with a larger natural dam in 1942. This landslide dam failed by overtopping and caused serious disasters in downstream valleys, killing 137 people due to several days of intensive rainfalls in 1951. A heavy rain activated the fourth landslide in 1979; as downstream residents had been evacuated before dam failure, no fatality was reported. The most recent landslide, in 1999, is described below.

\subsection{The Chi-Chi earthquake and the 1999 Tsaoling landslide}

The Chi-Chi earthquake $\left(M_{W}=7.6\right)$ was caused by a rupture along the Chelungpu fault. This earthquake, the most destructive of the 20th

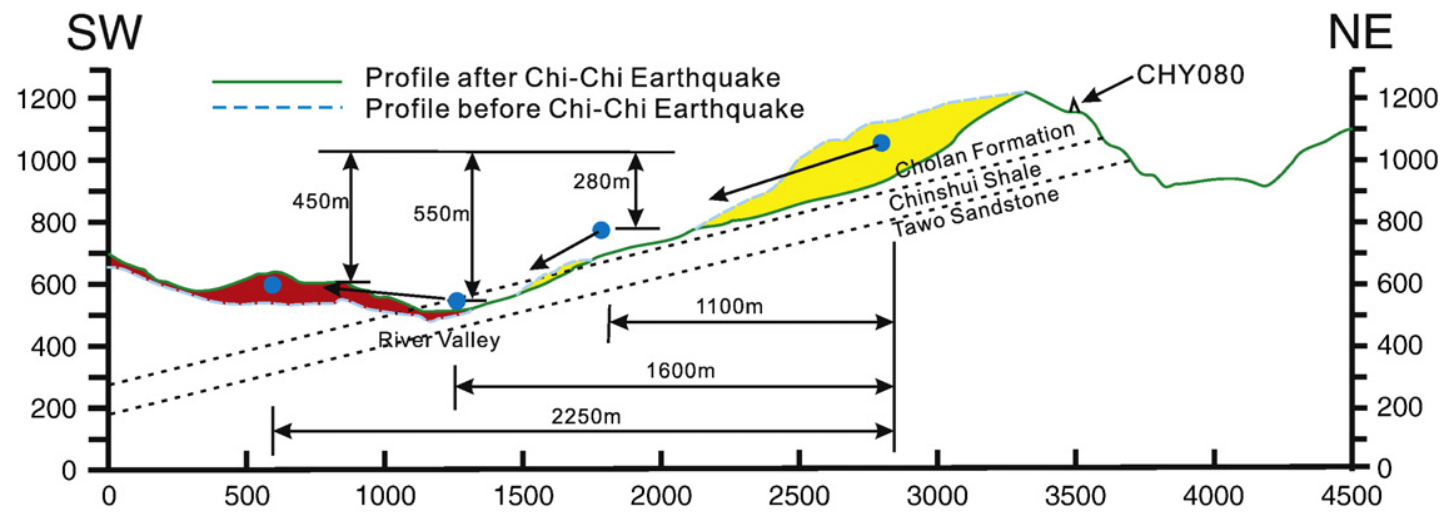

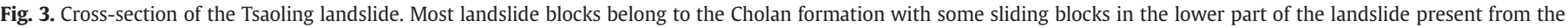

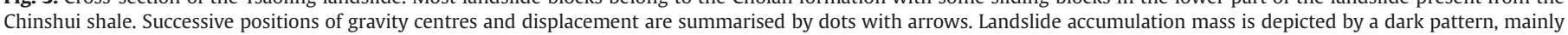
south of the river. The distance between the valley and sliding block is about $1600 \mathrm{~m}$ and the average sliding distance is about $2250 \mathrm{~m}$. 
century in Taiwan, struck the west-central island on September 21, 1999 (Kao and Chen, 2000; Angelier et al., 2001). A more than $90 \mathrm{~km}$ long surface rupture developed (Fig. 1a), involving thrusting and leftlateral components (Chen et al., 2001a,b; Lee et al., 2002). The vertical offsets averaged about $2 \mathrm{~m}$ along the southern half of the Chelungpu Fault and about $4 \mathrm{~m}$ along the northern segment, and horizontal offsets of 5 to about $8 \mathrm{~m}$ were observed along the northern part of the main fault (Yang et al., 2000; Yu et al., 2001). Tens of thousands of buildings collapsed and caused more than 10,000 casualties, including more than 2300 fatalities. Not only did urban areas suffer serious destruction, but also hydraulic facilities were severely damaged, including the rupture and displacement of dams and bridges, distortion and tumbling of riverbanks and coastal levees, and devastation of irrigation systems.

It is worth noting that the Chi-Chi earthquake triggered many landslides in Central Taiwan. Especially, the largest two disastrous landslides at Jiufengershan and Tsaoling killed 39 and 29 people, respectively. The 1999 Tsaoling landslide analysed herein was effectively triggered by the Chi-Chi earthquake in a mountainous area at a distance of about $30 \mathrm{~km}$ south-southwest of the epicentre (Fig. 1a). Correlations between the distance to the epicentre and specific ground motion parameters certainly deserve interest with regard to landslide generation together with local causes of gravitational instability such as lithology, structure and groundwater condition. This problem is seismologically complex and beyond the scope of the present study. Note, however, that the landslides triggered by the Chi-Chi event usually occurred within the area with PGA greater than 250 gal (Hung et al., 2002).

The Chi-Chi earthquake triggered the 1999 landslide at the same general location as the previous Tsaoling landslides (Table 1), with more than $125 \times 10^{6} \mathrm{~m}^{3}$ of rock and earth masses blocking the gorge of Chingshui River. A debris dam with heights of $50 \mathrm{~m}$ upstream and $150 \mathrm{~m}$ downstream suddenly formed, and the Tsaoling Lake having an estimated capacity of more than $46 \times 10^{6} \mathrm{~m}^{3}$ subsequently developed. Inflows from upstream drainage basin (an area of $162 \mathrm{~km}^{2}$ upstream of the landslide site) rapidly raised the water level of the lake and quickly expanded toward the upstream area.

The 1999 landslide was primarily made possible by failure in the lower Cholan Formation where shales are interbedded in sandstones. However, historical records show that the main detachment surfaces developed at a similar stratigraphic level (such as for the 1942 landslide), or at the boundary between the Cholan and Chinshui Formations (such as for the 1941 landslide) or even in the upper Chinshui Shale (such as for the 1979 landslide that started at a lower elevation in the mountain flank). From an engineering point of view, the Chinshui shale is a friable, silty mudstone with weak cementation that quickly deteriorates following wetting and drying. Although the shale layers interbedded in the sandstones of the lower Cholan Formation have similar properties, the cohesion and the residual friction angle of shales are significantly smaller in the lower Cholan Formation (149 $\mathrm{kPa}$ and $26^{\circ}$ on average, respectively, with water contents of $7.6 \%$ ) than in the Chinshui shales (451 kPa and $30^{\circ}$ on average, respectively, with water contents of 5.7\%), according to mechanical tests performed before the 1999 event by Lee et al. (1993). Together with the relationships between morphology and stratigraphic formations, this difference in rheological properties may explain why the slip surface of the 1942 and 1999 landslides could develop in the thin shale layers of the lower Cholan Formation, rather than in the thicker, underlying Chinshui shale; however, Lee (2001) provided other values for the Chinshui shale (on average, $779 \mathrm{kPa}$ for cohesion and only $13.4^{\circ}$ for friction, with water contents of $4.5 \%$ ). Yeng (2000) analysed the mechanical properties of the Chinshui shale and provided very low residual friction angles $\left(19,14\right.$ and $3^{\circ}$ for water contents of $2 \%, 4 \%$ and saturation) and zero cohesion at water saturation, but did not indicate corresponding values for the Cholan Formation.
The 1999 landslide mobilized about $125 \times 10^{6} \mathrm{~m}^{3}$ of rock and soil that slid across the adjacent Chingshui River, creating a large landslide dam (Fig. 2). Based on remote sensing analyses, the volume of disrupted material before river erosion was estimated to be $151.4 \times 10^{6} \mathrm{~m}^{3}$ and comparing this excess volume with the scar volume, $124.6 \times 10^{6} \mathrm{~m}^{3}$, Chen et al. (2006) determined a decompaction coefficient of $22 \%$ during the landslide event. The most dramatic feature of the 1999 landslide event was that only $20 \%$ (about $25 \times 10^{6} \mathrm{~m}^{3}$ ) of the sliding mass dropped into the Chingshui River, the rest of the sliding mass (about $100 \times 10^{6} \mathrm{~m}^{3}$ ) flied over the Chingshui River (Hung, 2000; Cheng, 2000). The distance between the valley axis and the sliding block was about $1600 \mathrm{~m}$ and the average sliding distance was about $2250 \mathrm{~m}$ (Fig. 3). Later the landslide dam was affected by very fast incision creating a deep canyon across the landslide mass accumulated in the bottom of the valley. It was concluded that 4 years after the 1999 event, the volume of landslide debris removed by river erosion was nearly $40 \times 10^{6} \mathrm{~m}^{3}$, which highlights the contribution of landslides to erosion (Chen et al., 2005, 2006).

The slip surface of the 1999 landslide was smooth and planar, parallel to the bedding (Fig. 3). It formed within alternating beds of fine sandstone and shale with ripple lamination or in shale. The shale is weathered by slaking and probably by sulfuric acid, which may be a major cause of intermittent slip (Chigira et al., 2003). The top margin of the 1999 landslide, in plan view, coincided with a V-shaped scarplet, which can be clearly recognized on aerial photographs taken before the landslide. Based on a recent study, this geomorphologic feature indicates that this landslide had already moved slightly after the 1979 event and prior to the 1999 event, providing precursory evidence (Chigira et al., 2003) in addition to the obvious general indication given by the preceding landslides at the same location.

\subsection{The role of groundwater}

Five boreholes were drilled in the Tsaoling area after the 1979 Tsaoling landslide (Hung et al., 2002). Two of these boreholes (BH4 and BH5) are located outside the landslide area. We utilized the three remaining boreholes two of which were $60 \mathrm{~m}$ deep and the third $120 \mathrm{~m}$ deep (BH1, BH2 and BH3, Fig. 4a) for our evaluation of groundwater table levels (Fig. 4b). In borehole BH3 located near to the peak of Tsaoling Mount and drilled to a depth of $120 \mathrm{~m}$ into the Cholan formation (that is, down to $928 \mathrm{~m}$ in elevation), no groundwater was encountered. In boreholes $\mathrm{BH} 1$ and $\mathrm{BH} 2$, which were drilled into the Chinshui shale, the water table was found at depths of $51 \mathrm{~m}$ and $42 \mathrm{~m}$ respectively, which meant $729 \mathrm{~m}$ and $583 \mathrm{~m}$ in elevation (respectively). We draw the groundwater table referring to the Lee et al. (1993) and the terrain of Tsaoling area (Fig. 4b).

Based on the structure and the water level data from these boreholes, a profile of groundwater table was proposed (Lee et al., 1993). In all the gullies in and below the breakaway valley, abundant water flow occurred even during the dry season. This observation implies that the gullies are located below the ground water table. In addition, no groundwater table was observed in the area from the crest of the breakaway valley to the head scarp, although a certain amount of water flow can be found in erosion gullies.

\section{The Newmark displacement method and 2D Distinct Element modelling}

We use the Newmark displacement method and a discrete granular simulation technique to investigate the mechanics of Tsaoling landslide. The major methodological and technical aspects of the numerical simulation are summarised below.

\subsection{Principle of the Newmark displacement method}

In 1965, N. M. Newmark first proposed the basic elements of a procedure for evaluating potential deformations of an embankment dam 

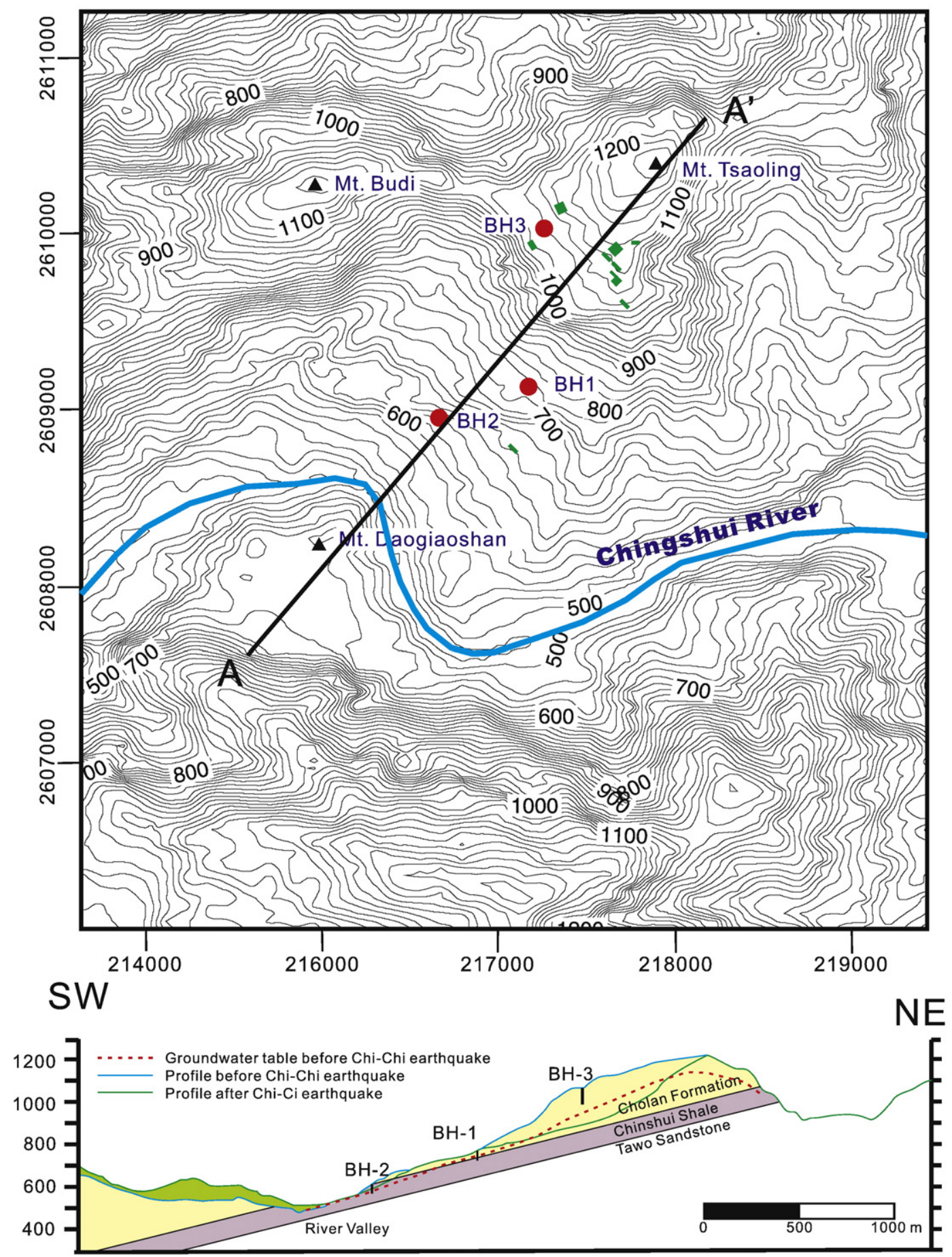

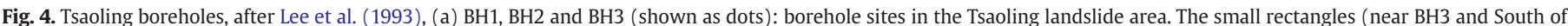

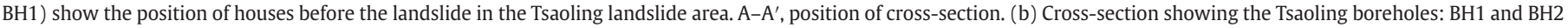
in the Chinshui shale met the groundwater table. BH3, drilled down to $120 \mathrm{~m}$ depth in the Cholan formation did not reach groundwater.

due to earthquake shaking (Newmark, 1965; Seed, 1979). By computing the ground motion acceleration at which the inertia force becomes sufficiently high to cause yielding, as shown in Fig. 5, and integrating the acceleration exceeding the yield acceleration in the sliding mass, the ultimate displacement can be evaluated. Huang et al. (2001) applied the Newmark displacement method to calculate the free-body force of the Jiufengershan landslide mass during the Chi-Chi earthquake, assuming that the block slid when the peak acceleration was beyond the yield acceleration. The free-body diagram illustrates the situation of the sliding block before the earthquake (Fig. 5). Thus the force normal to the slope is $m g \cos \delta$, where $m$ is the mass of the free-body, $g$ is the gravitational acceleration, and $\delta$ is the dip angle of the inclined surface.

A basal friction force $\mu_{s} m g \cos \delta$ consequently balances the $m g \sin \delta$ downslope force generated by gravity, so that the stability condition can be written:

$m g \sin \delta<\mu_{\mathrm{s}} m g \cos \delta+c A$,

where $\mu_{\mathrm{s}}$ is the coefficient of static friction, $c$ is the cohesive strength along the sliding surface, and $A$ is the area of the sliding surface. We 


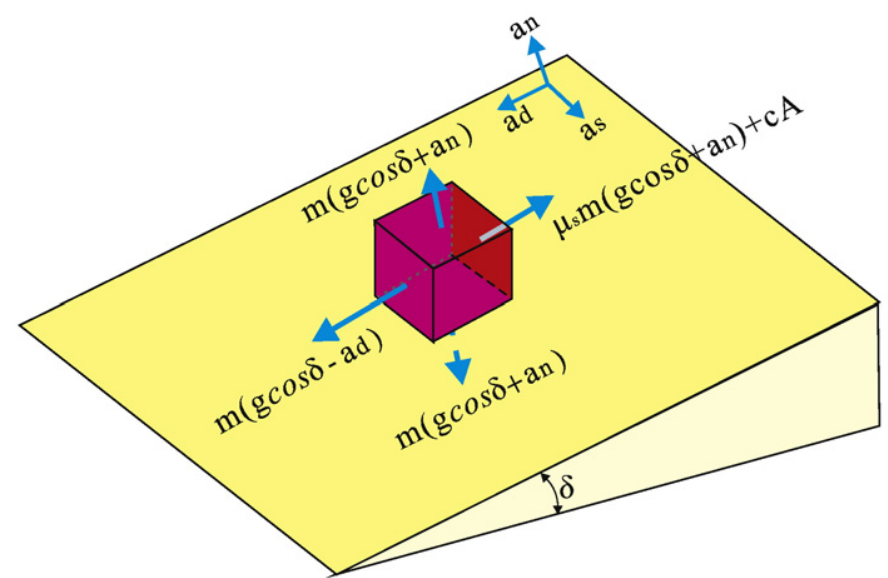

Fig. 5. Diagram illustrating the critical balance condition of forces exerted on a rock block lying on inclined planar surface under earthquake ground motion. See the text for details and explanation of the symbols.

adopted the cohesion of intact shale of $1.44 \times 10^{4} \mathrm{~N} / \mathrm{m}^{2}$ as indicated by Wieczorek et al. (1982), a density of $2.65 \mathrm{~g} / \mathrm{cm}^{3}$ and a dip $\delta=12^{\circ}$. We then introduce the factor of safety to evaluate the sliding threshold across an existing bedding plane. This safety factor, FS, is defined as follows (Newmark, 1965; Wilson and Keefer, 1983):

$\mathrm{FS}=\left(\mu_{\mathrm{s}} m g \cos \delta+c A\right) /(m g \sin \delta)$.

In the case of Tsaoling, FS is greater than 1, and we infer that sliding over an existing bedding plane is only possible if other external triggering mechanisms are present (earthquake or rainfall) or if the down-dip acceleration $a_{\mathrm{d}}$ is less than -180 gal.

However, the pore-pressure effect in quasi-static condition can markedly reduce the factor of safety and thus cannot be neglected. In addition, if the shear plane is parallel to stratification, which was the case at Tsaoling, the cohesion of intact shale should be regarded as an upper bound with respect to that of the contact. We conclude that the adopted value of $1.44 \times 10^{4} \mathrm{~N} / \mathrm{m}^{2}$ (the cohesion of intact shale) is certainly overestimated with respect to the actual value considering both the existing pore-pressure effect and the weak mechanical properties of the activated bedding interface.

To calculate the down-dip sliding acceleration, $S$, we used strong motion records of the accelerometric station CHY080 of the Central Weather Bureau located north to the crest of the Tsaoling landslide area (Fig. 3):

$S=\left(g \sin \delta-a_{\mathrm{d}}\right)-\mu_{\mathrm{s}}\left(g \cos \delta+a_{\mathrm{n}}\right)-c A / m$,

where $a_{\mathrm{d}}$ and $a_{\mathrm{n}}$ respectively refer to the down-dip oriented and normal-to-sliding components of acceleration.

\subsection{Distinct Element modelling and granular material simulation}

The numerical modelling technique that we adopted for the experiments reported herein involves a particular application, PFC2D, of a 2D Particle Flow code (Itasca, 2002). This technique is commonly used for the modelling of granular assemblages with purely frictional or bonded circular particles represented by discs. The original version of the Distinct Element Method (DEM) was devoted to the modelling of rock-block systems (Cundall, 1971); it was later applied to the modelling of granular material (Cundall and Strack, 1979). According to this method the global behaviour of an assembly of particles connected by a network of contacts is obtained by writing the equations of motion of each component for the whole particle set.

Before examining the numerical characteristics of our models it is necessary to mention few key-points related to the choice of 2D DEM tool. The use of a 2D code has important consequences regarding the kinematics of a sliding mass and the force transmission within a granular mass. Moreover, the 3D behaviour of a landslide cannot be modelled which precludes considering effects such as the lateral expansion (i.e., in the direction perpendicular to transport) during the landslide event. Note also that in the 2D DEM modelling the sliding mass is composed of rigid disks. This fact has several consequences. First, the shape of the disks differs from that of the actual blocks involved in a rock avalanche. Second, the behaviour of the whole modelled system is ruled by contact properties (elastic compliance and Coulomb's friction). In addition, the progressive surface damage and wearing of grains during the flow cannot be reproduced. The source of energy dissipation related to the non-elasticity of the impacts between grains cannot be modelled directly. Damping interaction between particles is generally introduced to accelerate the convergence of the numerical solution, and in the case of dynamical particle flow simulation, the numerical damping controls the coefficient of restitution of energy for individual grain-to-grain interaction. These simple interaction laws do not account for many of the deformation mechanisms involved in rock avalanche and debris flows. The limitations resulting from these restrictive hypotheses will be discussed in a later section based on the results of the numerical simulations.

The numerical model reproduces the experimental configuration as closely as possible. In this respect, the main source of discrepancy is the difference between the three-dimensional geometry of the actual configuration in the field and the two dimensional geometry that is introduced in the numerical model. The numerical model is intended as a slice of the laboratory one with a thickness equal to that of the 'vestolen' disks employed by Hutter et al. (1995) in experiments performed with two different granular materials and three different bed materials exhibiting a large range of behaviour expressed in different internal and bed friction angles. Thus, plane deformation is assumed, which means that out-of-plane movements are not considered, including out-of-plane rotations of the experimental disks.

\subsubsection{Numerical damping}

In this study, the influence of the numerical damping parameter needed to be analysed to verify the reliability of application. Because this parameter is not explicitly related to any physical mechanism, a realistic value must be obtained by back-analysis of the experimental data. A preliminary sensitivity analysis was performed which consisted of a series of numerical simulations with damping constant and damp 0.7 and 0 respective.

\subsubsection{Microproperties}

All numerical simulations by FFC require proper selection of microparameters by means of calibration processes in which the response of the numerical modelling as compared to the observed results of the physical material. Thus some attempts to improve and simplify the calibration procedure and the suggested procedure is suggested (Itasca, 2002; Potyondy and Cundall, 2004). Recently, application of experimental design and optimization to PFC model calibration in uniaxial compression test was proposed to calculate proper microparameters for model generation in order to closely reproduce macroproperties of the rock material such as uniaxial compressive strength (UCS), Young's modulus and Poisson's ratio (Yoon, 2007). For bond model, the microproperties for interaction of two circular particles are normal and shear stiffness, normal and shear bonds, and Coulomb friction coefficient must be obtained during the calibration step. Fakhimi (2004) proposed a slightly overlapped circular particle interaction (SOCPI) to resolve the failure envelope and the ratio of unconfined compressive strength to tensile strength which is usually lower than that of a rock. An application of dimensional analysis in calibration of a discrete element method for 
(a)

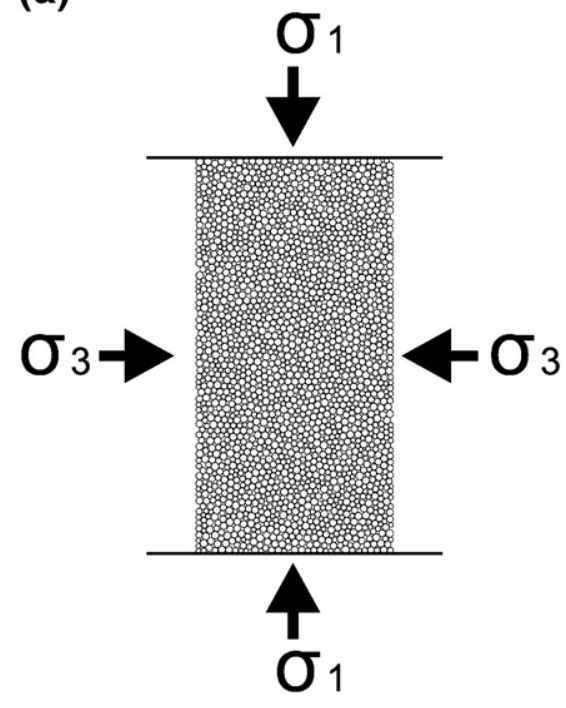

(b)

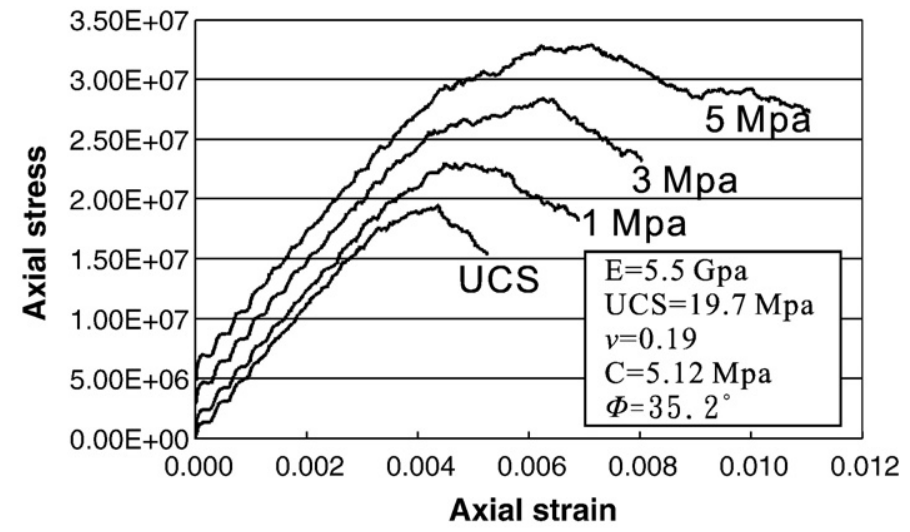

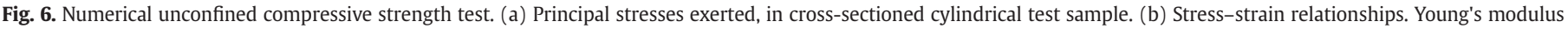

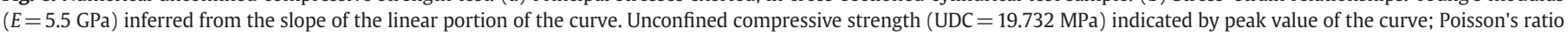
$(v=0.19)$ inferred from lateral strain and axial strain (not shown).

Pennsylvania Blue Sandstone was carried out to mimic the deformational and failure characteristics in stress paths (Fakhimi and Villegas, 2007). Although there is no straightforward solution from microproperties to macroproperties, some relations exist between the two properties for initial calibration as follows.

The Young's modulus of the material is linearly related to the value of contact stiffness. Parallel bonds increase the contact stiffness (Itasca, 2002). The Young's moduli of the grains and cement are expressed by:

$E_{\mathrm{c}}:=\left\{\begin{array}{l}\frac{k_{\mathrm{n}}}{2 t}, \text { PFC 2D disk mode } \\ \frac{k_{\mathrm{n}}}{4 R}, \text { PFC 3D, PFC 2D Sphere mode }\end{array}\right\}$

$\overline{E_{\mathrm{c}}}=k^{\bar{n}}\left(R^{(A)}+R^{(B)}\right)$.

Where $k_{\mathrm{n}}, R, t$ are particle normal stiffness, particle radius, and disk thickness (Potyondy and Cundall, 2004). Thus, Poisson's ratio depends both on the ratio of shear contact stiffness to normal contact stiffness and packing geometry. The peak strength of the material depends both on the friction coefficient and the bond strength (Itasca, 2002).

\subsubsection{Biaxial test}

In a particle code such as PFC, a compacted state cannot be prespecified in general, since there is no unique way to pack a number of particles within a given volume. The initial stress state cannot be specified independently of the initial packing since contact forces arise from the relative positions of particles. Finally, the setting of boundary conditions is more complicated than for a continuum modelling because the boundary does not consist of planar surfaces. A further difficulty arises when it is required to match the behaviour of a simulated solid (made of bonded particles) with a real solid tested in the laboratory. Potyondy and Cundall (2001), $E^{\prime}$ and $v^{\prime}$ are almost independent of $R / D$ and UCS $\left(q_{u}\right)$ of a synthetic material made of circular cylinders is not a function of $R / D$. The most efficient approach involves a trial-and-error process, because no complete theory can reliably predict macroscopic behaviour from microscopic properties and geometry.
In discrete element methods, the macroscopic behaviour of the granular media depends on the contact mechanical properties and there is no straightforward solution relating these parameters. Thus we performed a series of biaxial numerical tests on granular samples to derive the rock mechanical macroproperties of the granular assembly (Fig. 6). The 2D granular sample consists of 2574 disks. The numerical parameters obtained for an unconfined compressive test are the Young's modulus $E=5.5 \mathrm{GPa}$, the Poisson's ratio, $n=0.19$, and the unconfined compressive strength UCS $=19.732 \mathrm{MPa}$. The internal friction angle is $35.2^{\circ}$. The macroscopic properties of the numerical sample are similar to the properties of the rock samples from the Chinshui Shale and the Cholan Formation, as determined from laboratory tests (Yeng, 2000; Lee, 2001) (Table 2).

\section{Results of numerical experiments for the Tsaoling landslide}

The dimension of our numerical Tsaoling landslide model is $3800 \mathrm{~m}$ in length and $1208 \mathrm{~m}$ in height, consistent with field evidence (Figs. 1c and 3). Particular attention was devoted to geometry, displacement amplitudes, friction, cohesion and fragmentation levels each of which contribute strong constraints on mechanical behaviour during sliding.

\subsection{The model}

A profile of the slope was first built in order to perform a numerical simulation. In the numerical model the rocks located under the sliding surface (i.e., the footwall) are represented by "wall elements". Then, the particles composing the sliding mass are randomly generated

Table 2

Microproperties and macroproperties of models, as suggested by the results of a series of biaxial mechanical tests.

\begin{tabular}{llll}
\hline \multicolumn{2}{l}{ Parameters of the packing of disks } & \\
\hline Normal stiffness & $18.6 \mathrm{GN} / \mathrm{m}$ & Pb shear strength & $48,16,5.3 \mathrm{MPa}$ \\
Shear stiffness & $18.6 \mathrm{GN} / \mathrm{m}$ & Pb radius ratio & 0.8 \\
$\mathrm{~Pb}$ normal stiffness & $608 \mathrm{MPa} / \mathrm{m}$ & Friction of disk & 0.5 \\
$\mathrm{~Pb}$ shear stiffness & $608 \mathrm{MPa} / \mathrm{m}$ & Minimum radius & $1.05 \mathrm{~m}$ \\
$\mathrm{~Pb}$ normal strength & $48,16,5.3 \mathrm{MPa}$ & Rmax/Rmin & 4.0 \\
$\mathrm{~Pb}$ : Parallel bond & & & \\
\hline
\end{tabular}




\section{(a)}
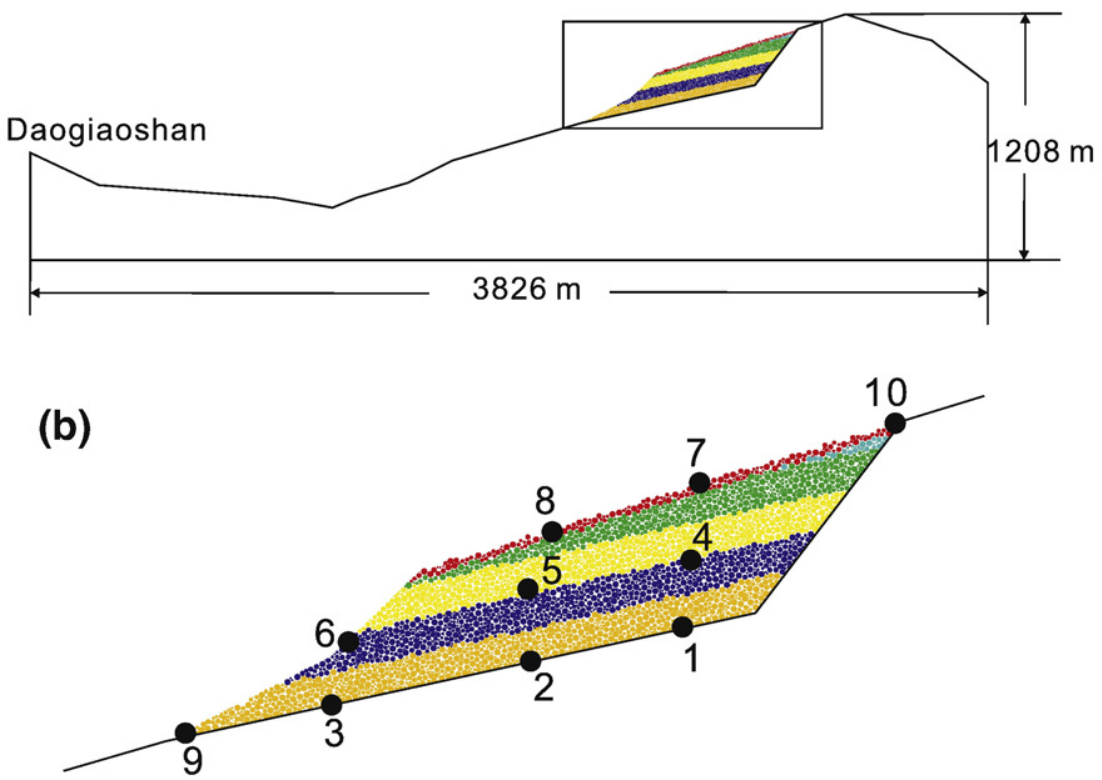

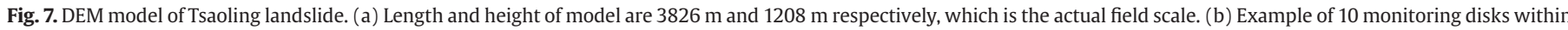

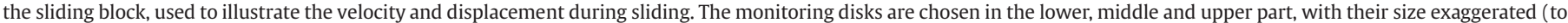
$20 \mathrm{~m}$ in diameter).

inside the whole deforming region (Fig. 7). The mechanical and geometrical properties of the elements are evaluated according to geological considerations. On the basis of in-situ observation in the landslide area, the adopted disk diameter ranges from $1.05 \mathrm{~m}$ to $4.40 \mathrm{~m}$, with a uniform distribution. Following these choices, the total number of particles is 3126 . The inter-particle friction and the base friction are set to 0.5 , which is the residual friction coefficient of joints in the rock mass (Table 2). The contact properties were chosen in agreement with the biaxial test results (Fig. 6). The strong motion vibration is applied to the model boundary by integrating the acceleration of the seismic station CHY080 recorded for the Chi-Chi earthquake (Fig. 8).

In our series of experiments, we adopted variable values for two major parameters of the numerical experiments, the residual friction coefficient at the landslide base and the internal bonding strength parameters. In the present paper, the residual friction coefficient ranges from 0.05 to 0.3 , and three different values of $48 \mathrm{MPa}, 16 \mathrm{MPa}$ and 5.3 MPa are used for parallel bond strength. The normal and shear stiffnesses, as well as the parallel bond radius ratios, are listed in Table 2 .

\subsection{Displacement amplitudes}

The displacement and down-dip sliding acceleration of monitoring disks during the vibrations are calculated during the shaking process. When the acceleration reaches the peak value, the sliding is triggered. In fact, two acceleration peaks exist beyond the yield acceleration (Fig. 9). After calculating the second integration of the peaks, we
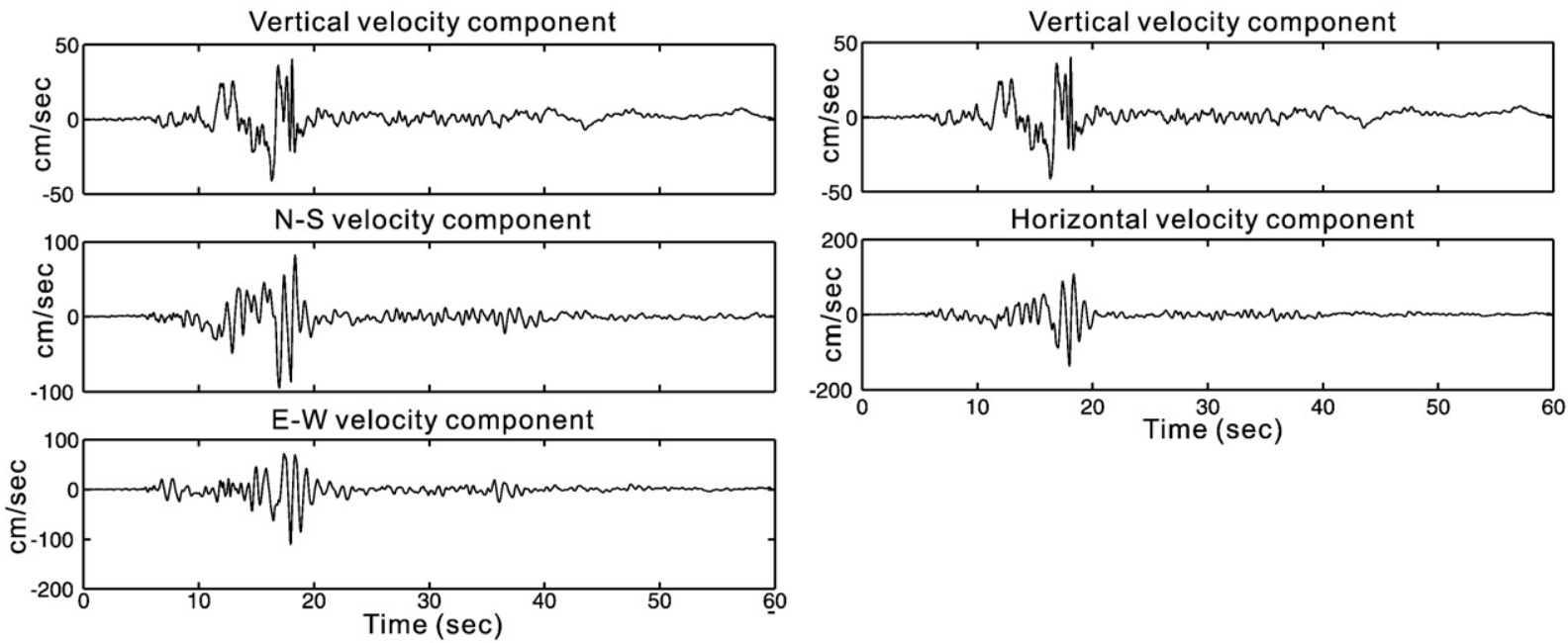

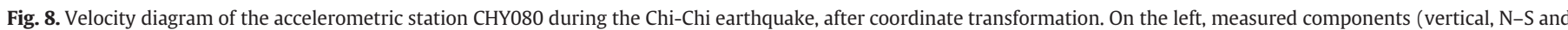
E-W). On the right, both the vertical component and the horizontal component along the slip direction of the Tsaoling landslide are shown. 

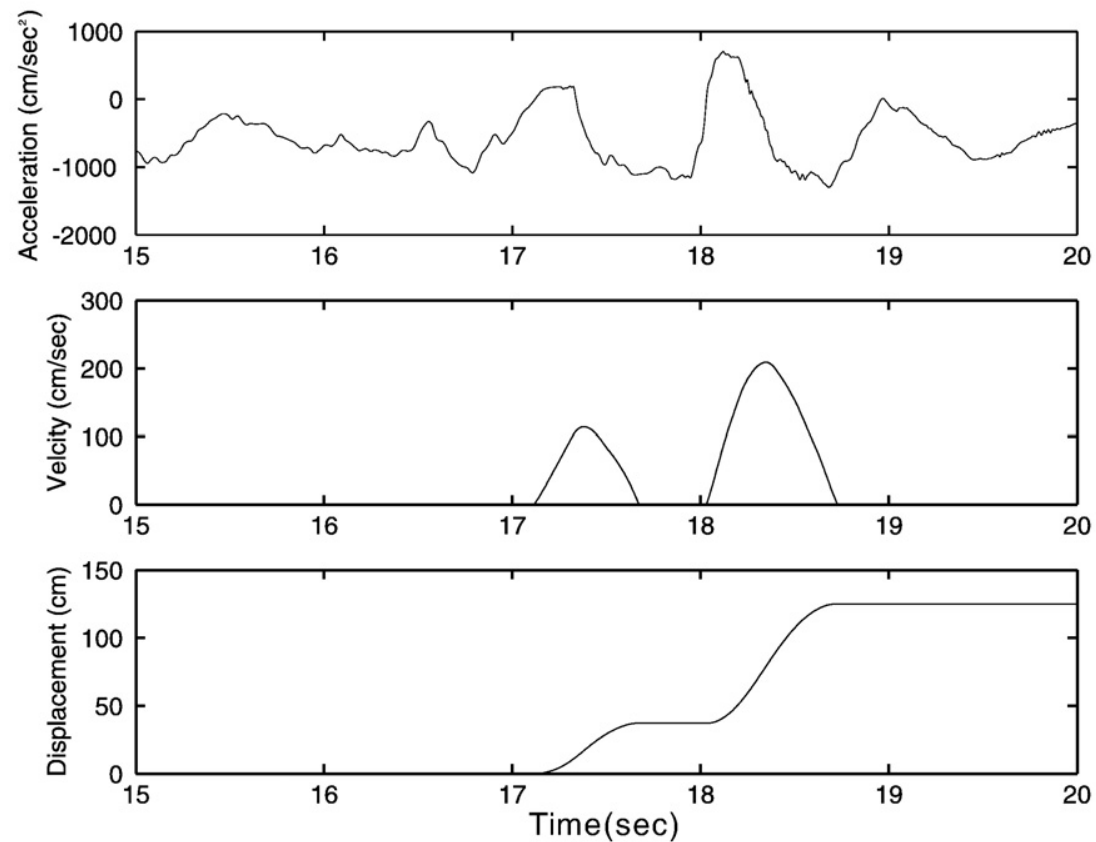

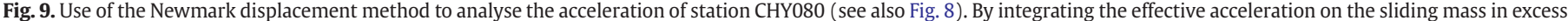
of this yield acceleration as a function of time, velocities and ultimately displacements of the slide mass could be evaluated.

found a total sliding value between block and sliding surface, as determined by the Newmark displacement method, of about $120 \mathrm{~cm}$ (Fig. 9).

We presumed that pore water pressures did not change significantly as the earthquake motions induced shear displacements along the surface of rupture just before the landslide event. According to our modelling, the blocks only slid by no more than $120 \mathrm{~cm}$ during the Chi-Chi earthquake, prior to the catastrophic event. The possible mechanisms of a seismically-induced landslide will be discussed on the basis of discrete particle simulations. At this stage, we assume that the peak friction applied in the numerical experiment decreases to the level of residual friction of the rock

As an example, Fig. 10 shows the displacements of disk 2 during the seismic shaking process with a peak friction of 0.78 and residual friction of 0.34 in the case of the Tsaoling landslide. In our simulations, the vertical and horizontal displacements of disk 2 reach $20 \mathrm{~cm}$ and $120 \mathrm{~cm}$ respectively which correspond to the values obtained from the Newmark displacement analysis.
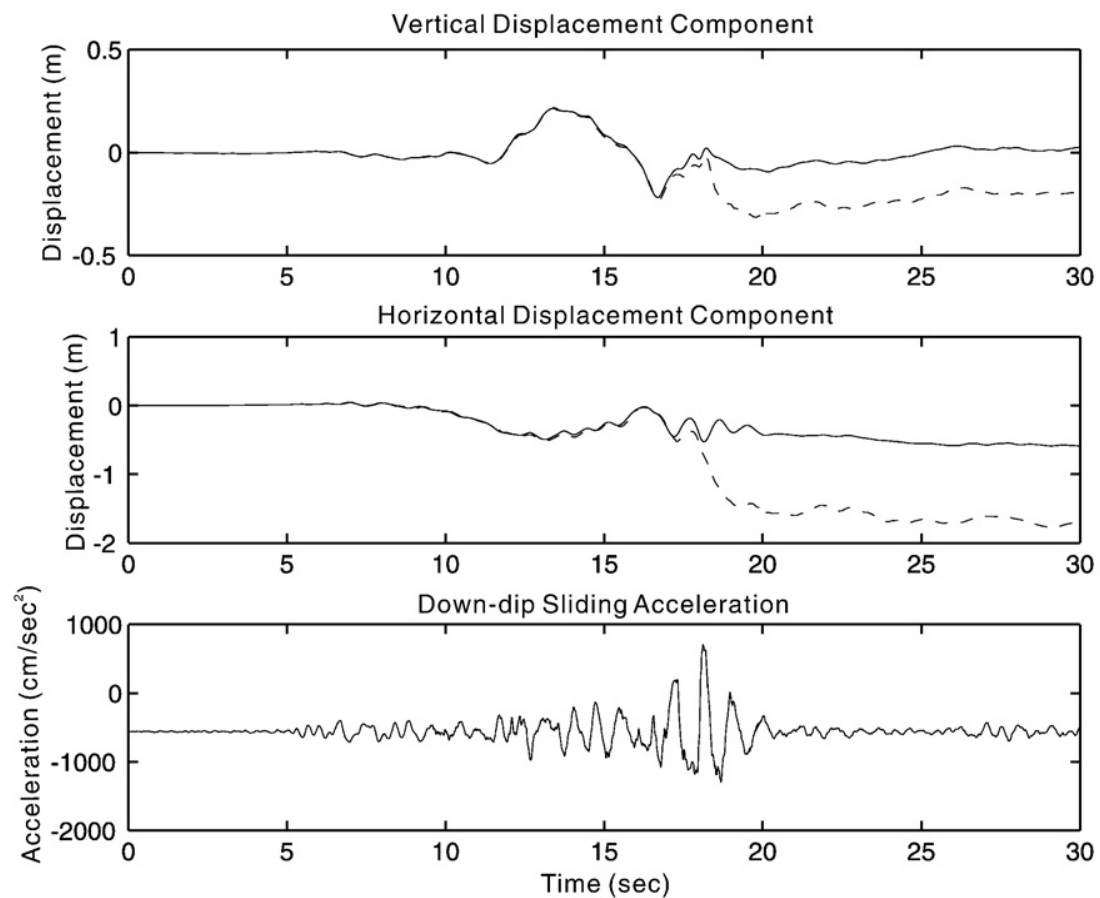

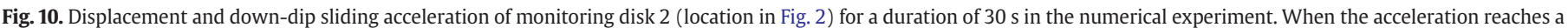

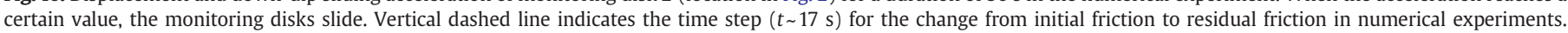
Residual friction angle for monitoring disk 2 is $18.9^{\circ}$ during boundary vibration. 


\subsection{Constraints on friction coefficients}

During the 1999 landslide at Tsaoling, not only did the blocks slide down the mountain slope but also $80 \%$ of the blocks crossed the Chingshui River and reached the opposite valley flank, many of them moving upslope. Because the geometrical configuration of the landslide is known, this particular aspect of the landslide motion provides constraints regarding the average friction and cohesion of the whole landslide. We consequently carried out a series of numerical simulations to better investigate the runout of the Tsaoling landslide in terms of the residual friction coefficient after the occurrence of the peak acceleration (Fig. 11). Not surprisingly, friction strongly influences the capacity of the landslide to reach the mountain slope on the southern side of the valley. We tested the following values of residual friction coefficients: $0.05,0.1,0.15,0.2,0.3$ and 0.78 . The total duration of seismic shaking was $160 \mathrm{~s}$.
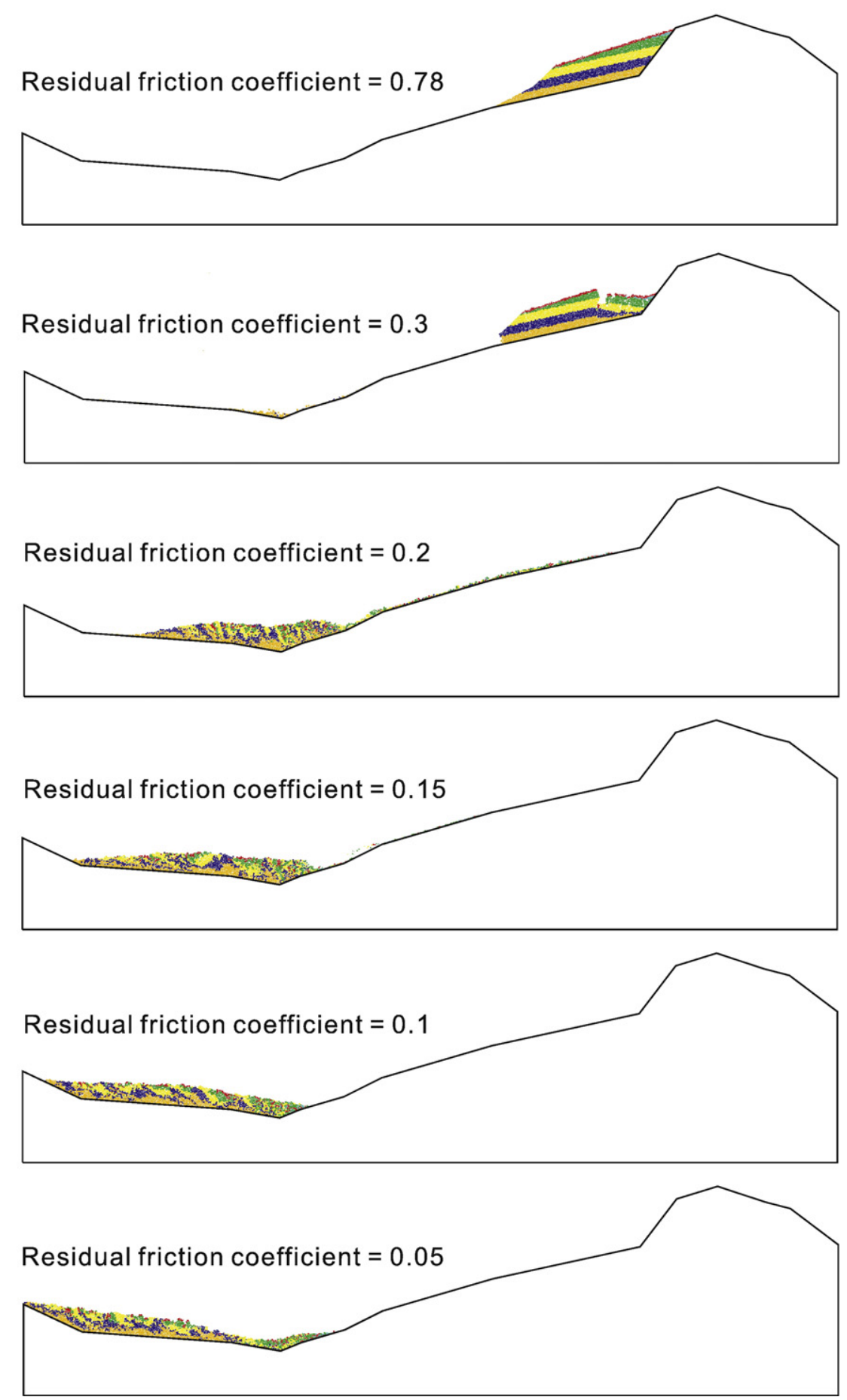

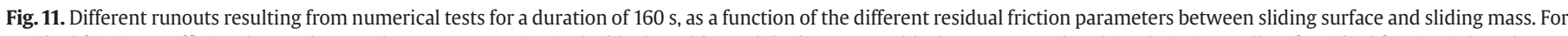

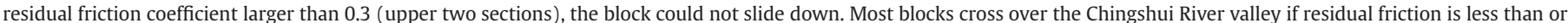

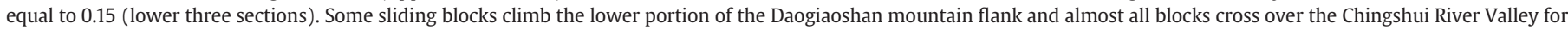

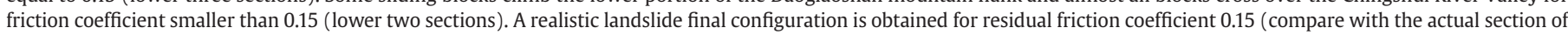
Fig. 3). 


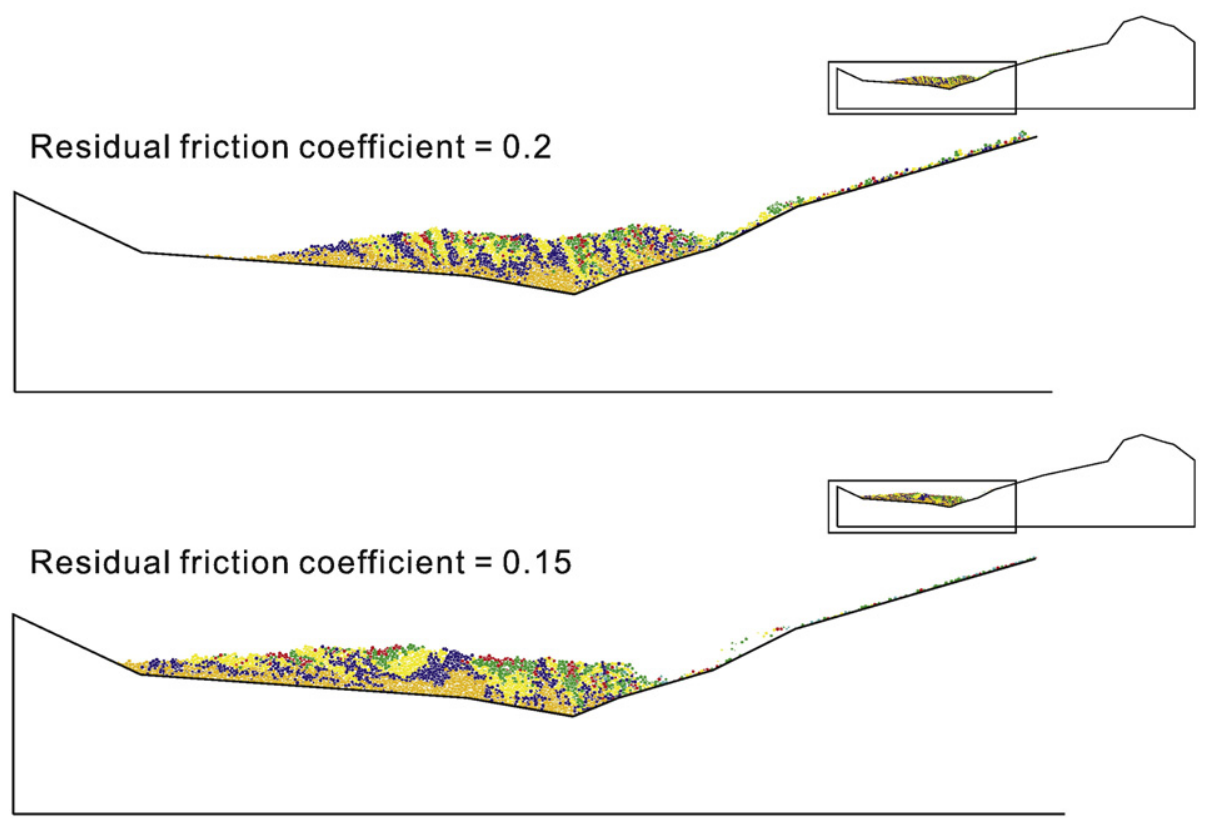

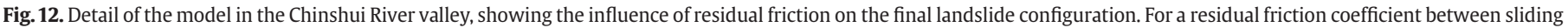

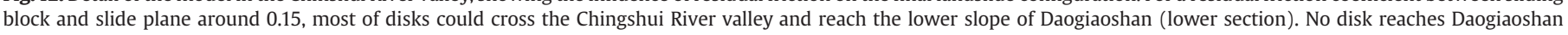

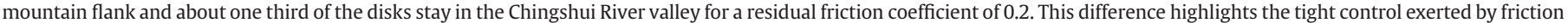
on landslide kinematics.

Numerical simulations indicated that if the residual friction coefficient is greater than 0.3 , the block could not slide down to the Chingshui River valley (Fig. 11). For a friction coefficient $\mu_{\mathrm{r}}=0.2$, some disks slide slowly and stop at the toe of the slope (Figs. 11 and 12). In this case, only a small part of the sliding disks can reach the opposite valley flank (Daogiaoshan). For $\mu_{\mathrm{r}}=0.15,80 \%$ of the disks cross over the Chingshui River valley (Figs. 11 and 12 ). For $\mu_{\mathrm{r}}=0.05$ to 0.1 , almost all the disks cross over the Chingshui River valley (Fig. 11). Despite the limitations of the 2D modelling as compared with the actual 3D configuration, we thus obtain constraints regarding the friction coefficient. Whereas relatively high $(0.2)$ or very low $(0.05-0.1)$ friction coefficients fail to reproduce the proportion of elements that actually crossed the river and went up on the opposite flank of the valley, the value $\mu_{\mathrm{r}}=0.15$ fits this requirement.

Knowing that numerous sources of uncertainties remain, such as for the 3D versus 2D behaviour, we conclude that a friction coefficient lower than 0.2 and higher than 0.1 probably well accounts for the actual behaviour of the Tsaoling landslide. This constraint from modelling is interesting because it favours low friction and tends to exclude both moderate values and very low values for friction.

\subsection{Constraints on bond strength and cohesion}

In addition to friction, the bond strength significantly influences the behaviour of a landslide. Fig. 13 shows the results of different parallel bond strength models with the residual friction coefficient determined above, that is $\mu_{\mathrm{r}}=0.15$. These models include three types of bonds defined as strong, weak and medium, with normal and shear strength values of $48 \mathrm{MPa}, 5.3 \mathrm{MPa}$ and $16 \mathrm{MPa}$ respectively (Table 2). Both the normal and shear stiffnesses of a parallel bond were fixed to $608 \mathrm{MPa} / \mathrm{m}$. The parallel bond ratio, defined as the ratio between the length of a parallel bond and the radius, takes the value 0.8 .

In the 'high strength model', the main body of the granular mass behaves roughly as a rigid block that slides down and crosses over the Chingshui River valley. A large part of the sliding block does not break out before it hits the Chingshui River valley. This scenario does not account for the actual behaviour of the landslide mass.
In the 'weak strength model', the main body becomes fragmented into small blocks before it reaches the toe of the slope. In this simulation, all of the particles of the upper layer tumble and collide, and are finally buried. This result is incompatible with field observations, especially the survival of people who were dragged by the landslide.

In the 'medium strength model', most of the middle part of the top layer was preserved and not buried. Note that one of the survivors lived in the middle part of the sliding block, which supports this result. We thus use the percentage of parallel bond that is broken as a constraint for the different sliding patterns before and after the collision with the bottom of the Chingshui River Valley during the time interval between 20 and $160 \mathrm{~s}$ (Fig. 14). It appeared that the medium strength model well accounts for both the actual levels of landslide fragmentation (contrary to the first model) and the low degree of burial of surface blocks (contrary to the second model).

\subsection{Evolution of fragmentation during the landslide event}

The different experiments summarised above brought constraints about the general behaviour of the landslide mass. In more detail, variations with time during the sliding process also deserve interest. Let us compare the 'weak strength model', the 'high strength model' and the 'medium strength model' in terms of the evolution of fragmentation. Fig. 14 shows the percentage of broken parallel bond as a function of time.

For the 'weak strength model', about $50 \%$ of the parallel bonds break after a sliding of about $20 \mathrm{~s}$ : after about $50 \mathrm{~s}$ of sliding, almost all the parallel bonds are broken. In this case, the parallel bonds break out before the displacement mass reaches the Chingshui River Valley. Thus, the sliding block becomes fragmented during sliding, and later the disks are free to roll and bounce. At this stage, the behaviour of cohesionless particles can be compared with that of a fluid. As mentioned before, this model did not account for the actual landslide behaviour.

Considering the 'high strength model' with strong bond strength, the sliding block remains poorly deformed for about $90 \mathrm{~s}$. Only about 

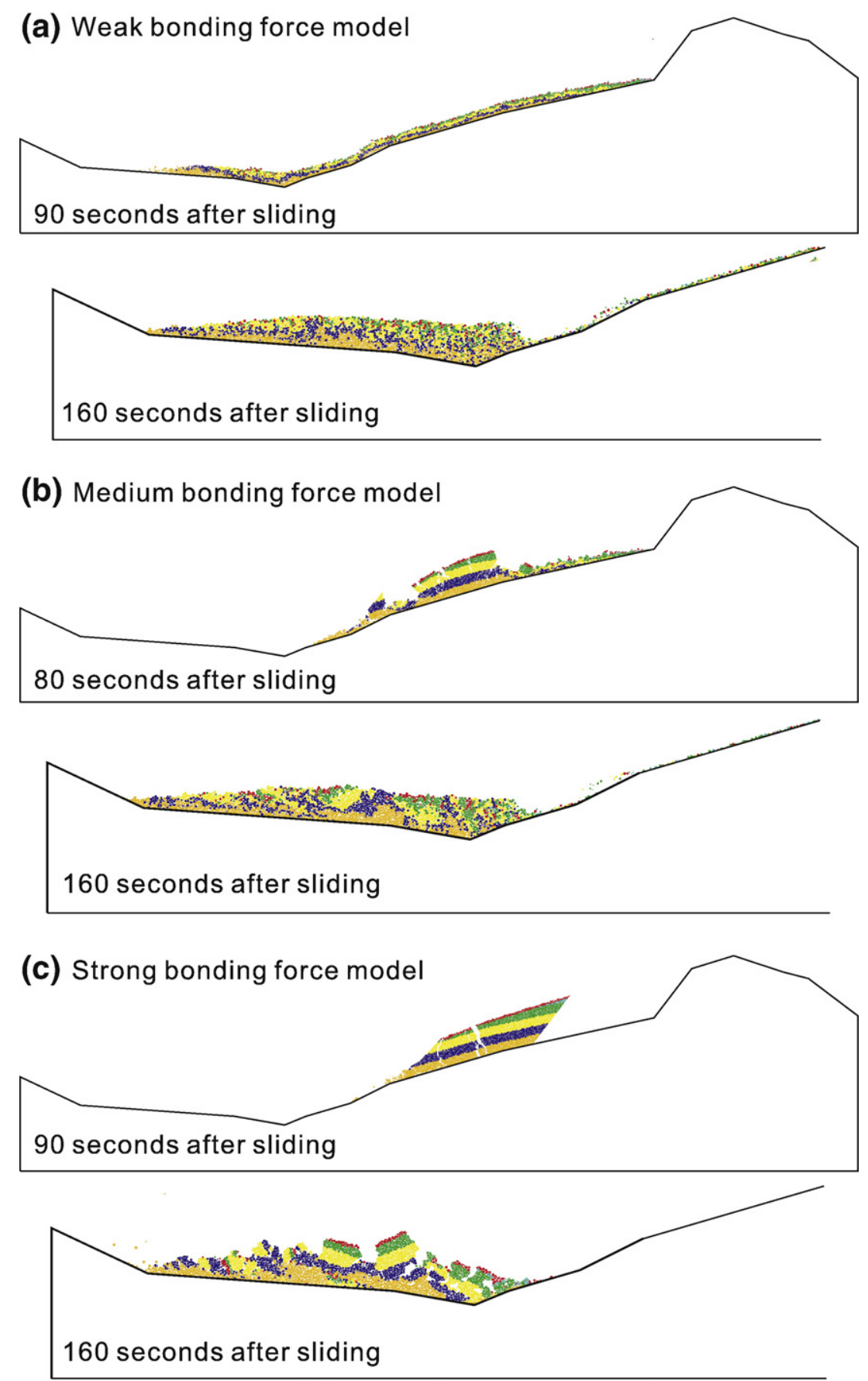

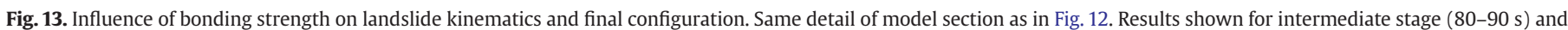

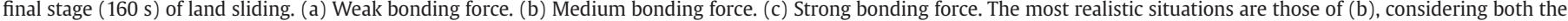
fragmentation level and the final configuration of the landslide mass (see discussion in text).

$5 \%$ breakage of the parallel bonds is predicted for this relatively long time span. A significant increase in fragmentation however occurs at about $140 \mathrm{~s}$, as a consequence of the collision between the sliding block and the bottom of the Chingshui River Valley. Only about $45 \%$ of breakage of parallel bond is predicted by the numerical model at the final stage.

Regarding the 'medium strength model', the first significant increase in bond breakage occurred after about 70 s, when $28 \%$ of the bonds were broken. A second remarkable increase in fragmentation happened at about $105 \mathrm{~s}$, because of the collision between the landslide mass and the bottom of the Chingshui River Valley. The maximum breakage of parallel bond predicted by the model is $95 \%$.
We conclude that not only does the medium strength model (as characterised by normal and shear strength values of $16 \mathrm{MPa}$, keeping in mind the previous constraint on the friction coefficient, that is, $\mu_{\mathrm{r}}=0.15$ ) explain the general structure of the landslide; it also well accounts for the timing of the fragmentation, as indicated by the field data and the reports about the disaster.

\section{Discussions}

Our Distinct Element numerical modelling of the 1999 Tsaoling landslide brings important physical constraints that can be compared with, and controlled by, field observations and reported disaster 


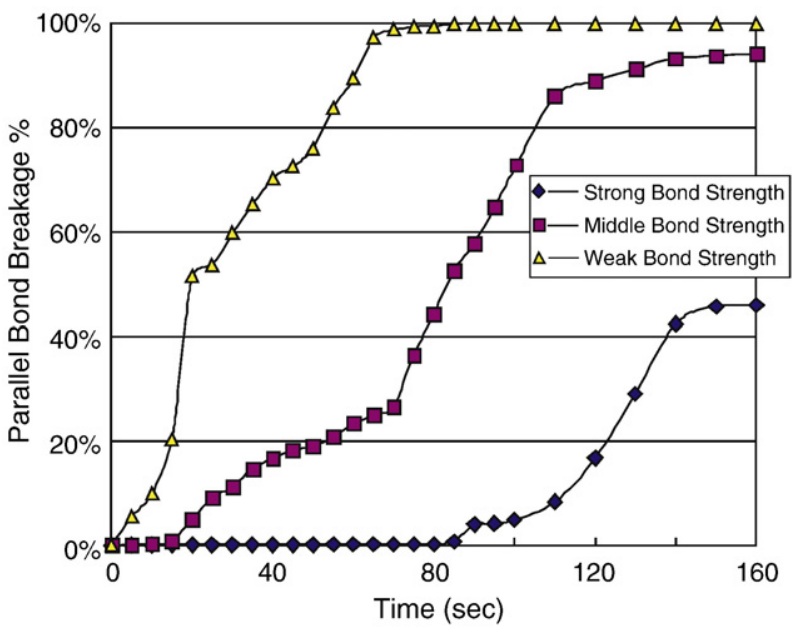

Fig. 14. Parallel bond breakages of three different parallel bond strengths during sliding. Compare with Fig. 13. For details, see text.

characteristics of this event. The most important constraints, discussed in the following three subsections, deal with slope stability, friction and possible lubrication mechanisms and runout distance. Regarding a few additional results, such as the landslide velocity, our modelling provides new insights but no original field datum exists that would allow comparison with, and checking of, our calculated values.

\subsection{Slope stability at Tsaoling during the Chi-Chi earthquake}

Our numerical modelling of the movement of the 1999 Tsaoling landslide triggered by the Chi-Chi earthquake took into account a variety of parameters related to gravity, earthquake vibration and ground motion, attitude of the sliding plane, sliding mass mechanical properties, as well as the peak and residual friction angles along the sliding basal surface. As shown earlier, a series of experiments indicated that to obtain realistic results with respect to actual observation the basal friction coefficient had to be lower than 0.2 and higher than 0.1. Thus, one question deals with a possible mechanism capable of reducing the friction coefficient along a sliding surface to such a low value, 0.15 on average. According to laboratory mechanical experiments with samples from the Chinshui shale and the Cholan formation with water contents of about 3.8\%-5.6\%, the residual friction angles are $13.4^{\circ}$ and $19.9^{\circ}$ respectively (Lee, 2001). This indicates that the residual coefficient of friction ranges between 0.23 and 0.36 , significantly larger than any acceptable value in our models. We consequently suggest that the lowest bound $(0.23)$, when combined with the reduction of effective normal stress due to pore water pressure, suffices to account for the reduction of the frictional strength to an apparent friction coefficient of 0.15 .

This hypothesis is qualitatively supported by the available hydrological data mentioned before, which suggested that the groundwater table crossed the sliding surface before the Chi-Chi earthquake (Fig. 4b). Not only did the groundwater saturate a large portion of the basal surface of the coming landslide, thus reducing the normal stress, it also diminished the internal cohesion in a significant volume of the above Cholan formation. Lee et al. (1993) indicated that the internal cohesion of the water-saturated shale could have reduced close to 0 . Our modelling brought some numerical constraints regarding the cohesion in the rock mass that was going to be affected by sliding, indicating medium strength.

In any case, the existence of low basal friction is supported by the final geometry of the landslide mass, especially considering the portion of the landslide that jumped over the Chingshui River valley at about $500 \mathrm{~m}$ in elevation and could reach about $700 \mathrm{~m}$ in elevation on the opposite mountain flank. This low friction also favoured high velocities of the landslide, but unfortunately the calculated velocities cannot be checked because of the lack of field measurements.

\subsection{Lubrication mechanisms}

During many rock slide events, the rock mass velocity, though high, remained smaller than about $10 \mathrm{~km} / \mathrm{h}$. For some large landslides such as that of the Vaiont disaster, much larger speeds were observed. Skemption (1966) consequently suggested that a zero friction was needed to explain a $300 \mathrm{~km} / \mathrm{h}$ speed at the end of the motion of the Vaiont landslide. In addition, Muller (1964) suggested the action of thixotropic phenomena. According to Habib (1975), if the shear rate becomes large enough, the liberated heat can transform the water inside the rock into vapour, resulting in the formation of a vapour cushion able to sustain the rock mass and lubricate the motion. If the slip surface is deep enough and planar, the rock mass may behave essentially as a rigid body perfectly supported by gas pressure because vapour develops at many points simultaneously (Chang et al., 2005).

In the Tsaoling case, we considered a thickness of the shear zone along the sliding surface of $0.5 \mathrm{~cm}$, a specific rock heat of $0.2 \mathrm{cal} / \mathrm{g}$, a rock density of $2.5 \mathrm{~g} / \mathrm{cm}^{3}$ and a porosity of 0.1 . Regarding the friction coefficient, based on the results of Lee (2001), the peak strength is 0.78 and the residual strength is 0.34 . Note however that the 0.34 value is larger than that issued from our modelling, and hence induces more frictional heat. Based on our numerical simulation, a sliding of $150 \mathrm{~cm}$ may produce heat of up to $293,000 \mathrm{cal} / \mathrm{m}^{2}$ in a very short time. The temperature of the sliding surface may thus increase to about $170{ }^{\circ} \mathrm{C}$ because of the frictional heat. However, such an evaluation should be considered with caution because the actual variations in friction throughout the sliding surface, which may be large, are unknown. Local friction coefficients lower than 0.15 or higher than 0.34 , respectively producing less and more heat with respect to the above evaluation certainly occurred but cannot be documented by actual data. The distance of $150 \mathrm{~cm}$ for initial heat-producing sliding is also an assumption. Thus our rough evaluation simply shows that even taking the pressure at such shallow depths into account the increase in temperature induced by frictional heat is likely to have vapourized, at least locally, the pore water near the sliding surface. The normal effective stress, and hence the effective friction, may thus have decreased to very low values after a small initial displacement, resulting in high velocity for the subsequent sliding.

Recently, Vardoulakis (2002) further suggested that because of the speed of the sliding process, heat could be trapped inside the shear band, rapidly producing a pore-pressure explosion due to the thermoplastic collapse of the clay gouge, as was suggested for the Vaiont slide of October 1963. This thermoplastic collapse of the clay gouge quickly induces a total loss of shear strength and uninhibited sliding motion along a frictionless basal surface (Chang et al., 2005). This scenario is however not suggested for the Tsaoling landslide, because we could not find any appropriate clay gouge layer along the sliding surface. However, a strain rate softening associated with accelerated motion should also deserve consideration.

In any case, considering the Tsaoling landslide, field observation suggested, and our modelling confirmed, that the characteristics of the long runout length landslide implied a low coefficient of basal friction, about 0.15 . The most likely explanation of this low friction along the sliding surface is the reduction of efficient friction coefficient because of pore-fluid pressure. To this respect, it is worth noting that among five major dip slope failures that occurred in Tsaoling during the 19th and 20th centuries at least two events were triggered by heavy rainfall (Table 1). Despite the absence of accurate measurements of water table levels in distant times, an obvious correlation exists between landslide events and two kinds of triggering phenomena: large rainfalls and earthquakes. Whether or not hydraulic fracturing occurred just prior to the landslide event is 


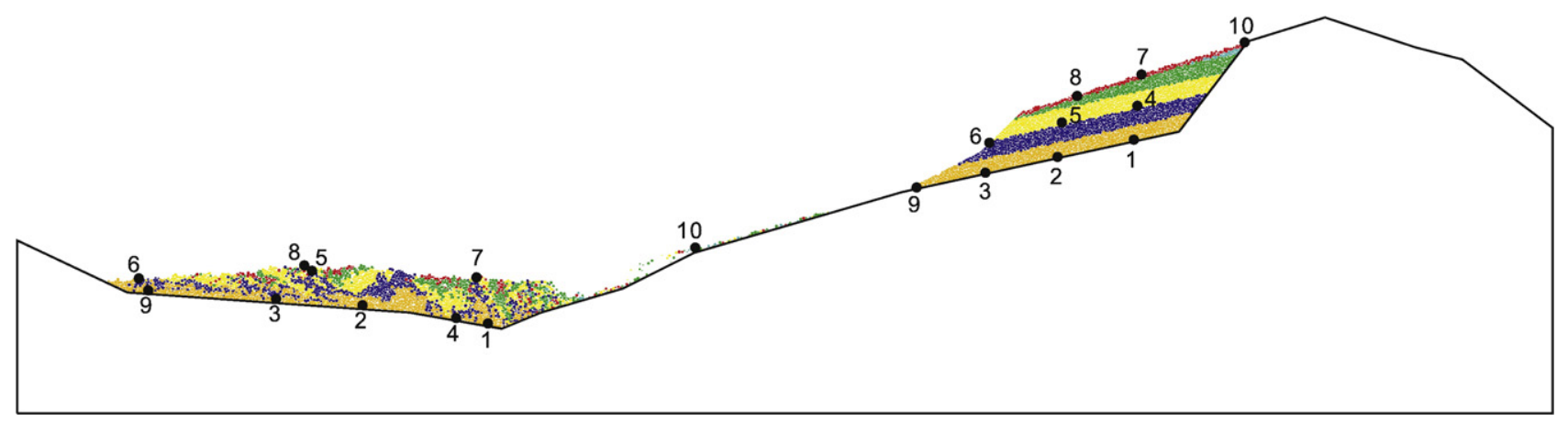

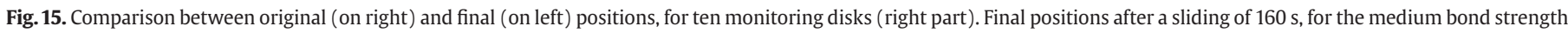

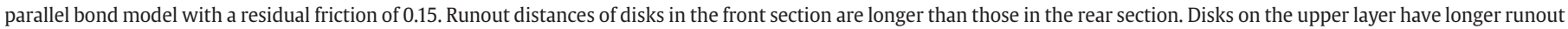
distances than those located in the lower layer.

unknown. Better quantification of pore-pressure effects and evaluation of their role to diminish the basal friction and weaken the rock mass above deserve future investigation.

The importance of fluid behaviour has been questioned for the large landslide structures on the Moon and Mars (Howard, 1973; McEwen, 1989). This problem has led to explore the possibility that landslides move as granular flows without the need of interstitial fluid for lubrication (Campbell, 1989; Cleary and Campbell, 1993). The selflubrication hypothesis is based on the simulation of granular flow, in which the sliding mass flows over a dilute layer of highly agitated particles, even in a dry environment. This deformation mechanism can explain low friction observed at the sliding surface. However, a finite granular mass released on an inclined plane does not show the expected sheared basal layer and has an upward-decreasing density (Campbell et al., 1995).

\subsection{Runout distance}

We use the medium strength model to illustrate the runout distances, taking ten monitoring disks as an example (Fig. 15). The initial length of the sliding block is $896 \mathrm{~m}$ from monitoring disk 9 to disk 10, and the length of deposit area is $1280 \mathrm{~m}$. The runouts and maximum velocities of the monitoring disks are listed in Table 3. During sliding, the disks located in the downslope area collided with the disks in the rear, which underwent acceleration in the downslope direction. The monitoring disks in the downslope area (disks 5, 6, and 9) provided longer runout distances (about $2100 \mathrm{~m}$ ). The monitoring disks in the middle section formed a disordered pattern because the disks consumed kinetic energy due to randomly directed collisions.

Let us consider three disks, 3, 6 and 9, near the front of the landslide mass (Fig. 15). Before land slide event, disk 9 was located at the front of the landslide whereas disks 3 and 6 situated at a distance of about $200 \mathrm{~m}$ behind this front, with disk 6 near the upper surface and disk 3 near the base. After the landslide, disks 6 and 9 have undergone large displacement (about $2 \mathrm{~km}$ ), but disk 6 has remained close to the free surface whereas disk 9 has been buried. Disk 3 has remained close to the basal surface, but its runout distance is significantly shorter than for disk 6 , with a difference of about $380 \mathrm{~m}$. This example shows that blocks located at the surface near the landslide front may pass each other during sliding and be buried, whereas blocks located near the basal surface of the landslide show significantly shorter runout distances and do not move towards the surface. Fig. 15 also shows that the relative positions of the blocks located in the middle and upper portions of the landslide undergo smaller variation, such as for disks 8, 7,1 and 5. However, some blocks may change in depth inside the sliding mass (disk 4) or show smaller runout distances (disk 2 near landslide base, compare with disks 5 and 8 ). Not surprisingly, some disks located at the rear of the landslide mass may even rest on the surface after sliding (disk 10, compare with disk 7).

The real displacements of blocks at depth cannot be checked, but the blocks located at the free surface field observation clearly confirmed the different behaviours illustrated in Fig. 15 (e.g., disks 9, $6,8,7$ and 10). In general, the runout distances of disks located in the downslope section are longer than the disks in the rear section, and the disks from the upper layers have longer runout distances than those located in deeper layers. These differences well account for the actual behaviour of the 1999 Tsaoling landslide, as documented from field observation and disaster reports, and they are easily explained by the smaller pressure, and hence the larger freedom to move, for the rocks near the surface and front part of the landslide mass.

\subsection{Rolling resistance}

For a realistic modelling of rock mass falls besides viscous damping, the rolling resistance should be taken into account, because the rolling resistance is induced by the rolling body and the deformation of the ground (Preh and Poisel, 2007). Poisel and Roth

Table 3

Summary of results regarding the runout distances and maximum velocity of monitoring disks, for a friction coefficient of 0.15 and three bonding strengths.

\begin{tabular}{|c|c|c|c|c|c|c|c|c|c|c|}
\hline Disks & 1 & 2 & 3 & 4 & 5 & 6 & 7 & 8 & 9 & 10 \\
\hline \multicolumn{11}{|l|}{ Medium bonding strength } \\
\hline Distance (m) & 1721 & 1761 & 1790 & 1814 & 1896 & 2138 & 1781 & 1946 & 1913 & 1430 \\
\hline Maximum velocity (m/s) & 29.2 & 35.2 & 44.5 & 27.7 & 39.3 & 39.5 & 32.0 & 36.5 & 35.5 & 35.2 \\
\hline \multicolumn{11}{|l|}{ Strong bonding strength } \\
\hline Distance $(\mathrm{m})$ & 1811 & 1812 & 1719 & 1853 & 1947 & 2100 & 1814 & 1882 & 2022 & 1891 \\
\hline Maximum velocity (m/s) & 34.7 & 34.6 & 35.9 & 31.4 & 30.3 & 36.3 & 31.4 & 30.7 & 32.6 & 33.7 \\
\hline \multicolumn{11}{|c|}{ Weak bonding strength (*indicates particles travelling over the Daogiaoshan Mtn). } \\
\hline Distance $(\mathrm{m})$ & 1726 & 1765 & 1764 & 1716 & 1848 & 1620 & 1724 & 1811 & Unknown* & 1117 \\
\hline Maximum velocity $(\mathrm{m} / \mathrm{s})$ & 33.6 & 40.5 & 39.1 & 34.5 & 38.1 & 39.2 & 33.1 & 36.3 & Unknown* & 24.2 \\
\hline
\end{tabular}


(2004) had proposed that the angular velocity of particles in contact with wall element should be adopted in very time step in order to take account rolling resistance because the pure rolling of blocks in the model leads to more extensive runouts that are observed in nature. Preh and Poisel (2007) highlighted that the rolling resistance is a function of the ratio of the eccentricity to the radius in classical mechanics. It means that spherical blocks of different sizes should have the same rolling resistance coefficient. But Preh and Poisel (2007) also highlighted that large blocks generally have a longer runout than smaller ones, thus they suggested calibrating the runout by the sag $u_{\mathrm{rr}}$. They carried out a series of numerical experiments with an irregular assembly of particles of two different sizes of $0.8 \mathrm{~m}$ and $1.6 \mathrm{~m}$. They found that the larger particles have a longer runout than smaller ones and the smaller particles rest at the bottom and the larger particles rest at the top within the deposit mass. Their model observation is closely similar to that in nature. In the case of Tsaoling landslide, the rolling resistance should play a minor role in strong bonding force model. In this case, the sliding along the slope is the major mechanism (Fig. 13c). However, in the weak bonding force model (Fig. 13a), the bond breakage reaches to almost 100\% at the final stage of sliding on the slope (Figs. 13a and 14), thus these particles act as a flow-like avalanche. In this case, the rolling resistance plays an important role of controlling the runout distance and deposition.

\subsection{Possibility of survival following the Tsaoling landslide}

Based on our numerical simulation we can discuss in more detail the possible reasons for survival of inhabitants after this seismicinduced Tsaoling landslide. The strength of the buildings is not taken into account herein; we only consider the behaviour of the underlying landslide. In this respect, two crucial parameters are the disruption of the landslide mass and the possibility of burial or overturning during the transport.

Our weak strength model indicates that most of the parallel bonds are broken after the collision with the Chingshui River valley basin (Figs. 13a and 14). Most of the particles of the upper layer are thus being buried or continue rolling, so that the suggested probability for survival is low within the domain that reached the valley. The actual count of survivals after the catastrophe supports this conclusion. In our strong and medium strength model, most portions of the sliding block behave as quasi-rigid blocks during sliding (Fig. 13b and c). After striking the valley, most of the kinetic energy dissipates and the remaining kinetic energy pushes the particles toward Daogiaoshan. In general, the particles of the front and the rear side are buried during and after the collision, but the behaviour of the middle part differs because the upper layer remains at the upper surface of the sliding block and more or less keeps consistent (Fig. 13b and c). These results suggest that the probability for survival was much higher in the middle part of the sliding block than elsewhere in the landslide.

\subsection{The Tsaoling landslide as a case example for future studies}

The 2-D discrete element simulation of the major 1999 Tsaoling landslide induced by the Chi-Chi earthquake strongly supports the contention of a high reduction of friction at the sliding basal surface, as the only way to explain the capacity of this landslide to reach its observed maximum elevation on the opposite side of the valley. A selflubrication mechanism is suggested in our study to explain the low residual friction calculated, about 0.15 . This low friction favoured the propagation of more than $125 \times 10^{6}$ of cubic metres of rock debris which crossed over and collided against the Chingshui River valley. Our modelling also suggests that the maximum velocity of the landslide may have reached about $50 \mathrm{~m} / \mathrm{s}(180 \mathrm{~km} / \mathrm{h})$, but no actual measurement is available to confirm or invalidate this determination. A quasi-rigid behaviour of the central portion of the sliding mass during the landslide event may explain the presence of 7 survivors after $2250 \mathrm{~m}$ of sliding. In contrast, the weak strength model would predict extensive disruption of the sliding block during sliding, so that in this case the particles of the upper layer would have been rolling and buried, resulting in extremely low probability for survival. In any case, our modelling also indicated that in the strong strength model most of the sliding material would not have suffered pervasive disruption after striking the bottom of the Chingshui River valley so that the downslope portion of the landslide would never have reached the opposite mountain flank of Daogiaoshan.

\section{Conclusions}

Based on the 1999 Tsaoling case, we thus conclude that numerical modelling utilizing a variety of available observations and measurements (including morphology, structural geology and stratigraphy, hydrology, rock mechanics, location of survivors and so on) has the potential to bring tight constraints on landslide behaviour. Because it was possible to consider that in the first approximation the edges of the landslide could be considered as more or less perpendicular to the transport direction, the modelling could be performed in two dimensions, involving an implicit condition of null displacement and strain perpendicular to transport. It is unlikely that a more complex 3D modelling would provide different conclusions in the Tsaoling case. More information should be brought by field measurements prior to, and during future events, for instance concerning the fluid behaviour at depth. However, for landslide areas where this geometrical condition is far from being satisfied, 3D modelling would be compulsory.

\section{Acknowledgements}

We are grateful to Editor Giovanni Crosta and two anonymous reviewers for useful comments that allowed us to improve our analysis. Suggestions from, and discussions with Chyi-Tyi Lee, KehJian Shou, Alfredo Taboada and Kuo-Jen Chang were much appreciated. This research was supported by grants from the National Science Council of Taiwan (NSC94-2119-M-002-021 and NSC97-2116M-002-012). It is also made in the frame of the Associated International Laboratory (LIA) ADEPT supported by the French CNRS-INSU and the National Science Council of Taiwan.

\section{References}

Angelier, J., Lee, J.-C., Chu, H.-T., Hu, J.-C., Lu, C.-Y., Chan, Y.-C., Lin, T.-J., Font, Y., Deffontaines, B., Tsai, Y.-B., 2001. Le Séisme de Chichi (1999) et sa place dans l'orègene de Taiwan. Comptes Rendus de l' Académie des Sciences, Series IIA, Earth and Planetary Science 333, 5-21.

Campbell, C.S., 1989. Self-lubrication for long runout landslide. Journal of Geology 97, 653-665.

Campbell, C.S., 1990. Self-lubrication for long runout landslide: a reply. Journal of Geology 98, 794-796.

Campbell, C.S., Cleary, P.W., Hopkins, M., 1995. Large-scale landslide simulations: global deformation velocities and basal friction. Journal of Geophysial Research 100, 8267-8283.

Central Geological Survey (CGS, MOEA), Surface ruptures along the Chelungpu fault during the Chi-Chi earthquake, Taiwan (1999) 25,000:1, 4 maps.

Chang, K.-J., Taboada, A., Lin, M.-L., Chen, R.-F., 2005. Analysis of landsliding by earthquake shaking using a block-on-slope thermo-mechanical model: example of Jiufengershan landslide, central Taiwan. Engineering Geology 80, 151-163.

Chen, H., Lee, C.F., 2000. Numerical simulation of debris flows. Canadian Geotechnical Journal 37, 146-160.

Chen, H., Lee, C.F., 2003. A dynamic model for rainfall-induced landslides on natural slopes. Geomorphology 51, 269-288.

Chen, W.-S., Huang, B.-S., Chen, Y.-G., Lee, Y.-H., Yang, C.-N., Lo, C.-H., Chang, H.-C., Sun, Q.-C., Huang, N.-W., Lin, C.-C., Sung, S.-H., Lee, K.-J., 2001a. 1999 Chi-Chi earthquake: a case study on the role of thrust-ramp structures for generating earthquake. Bulletin of Seismicity of the Social America 91, 986-994.

Chen, Y.-G., Chen, W.-S., Lee, J.-C., Lee, Y.-H., Lee, C.-T., Chang, H.-C., Lo, C.-H., 2001b. Surface rupture of 1999 Chi-Chi Earthquake yields insights on active tectonics of central Taiwan. Bulletin of Seismicity of the Social America 91, 977-985.

Chen, T.-C., Lin, M.-L., Hu, J.-J., 2003. Pseudo-static analysis of Tsaoling rockslide caused by Chi-Chi earthquake. Engineering Geology 71, 31-47. 
Chen, R.-F., Chan, Y.-C., Angelier, J., Hu, J.-C., Huang, C., Chang, K.-J., Shih, T.-Y., 2005. Large earthquake-triggered landslides and mountain belt erosion: the Tsaoling case, Taiwan. Comptes Rendus Géoscience, Académie des Sciences Paris, 337, 1164-1172.

Chen, R.-F., Chang, K.-J., Angelier, J., Chan, Y.-C., Deffontaines, B., Lee, C.-T., Lin, M.-L. 2006. Topographical changes revealed by high-resolution airbone LiDAR data: the 1999 Tsaoling landslide induced by the Chi-Chi earthquake. Engineering Geology $88,160-172$.

Cheng, H.-H., 2000. Photogrammetric Digital Data Processing of Tsao-Ling Big Landslide. ACRS, Taipei. Conference Poster.

Cheng, Y.-P., Nakata, Y., Bolton, M.D., 2003. Discrete element simulation of crushable soil. Géotechnique 53 (7), 633-641.

Chigira, M., Wang, W.-N., Furuya, T., Kamai, T., 2003. Geological causes and geomorphological precursors of the Tsaoling landslide triggered by the 1999 ChiChi earthquake, Taiwan. Engineering Geology 68, 259-273.

Cleary, P.W., Campbell, C.S., 1993. Self-lubrication for long runout landslides: examination by computer simulation. Journal of Geophysical Research 98 (B12), 21911-21924.

Crosta, G., 1998. Regionalization of rainfall thresholds: an aid to landslide hazard evaluation. Environmental Geology 35, 131-145.

Crosta, G.B., Imposimato, S., Roddeman, D.G., 2003. Numerical modeling of large landslides stability and runout. Natural Hazards and Earth System Sciences 3, 523-538.

Crosta, G.B., Imposimato, S., Roddeman, D.G., 2006. Continuum numerical modeling of flow-like landslides. In: Evans, S.G., et al. (Ed.), Landslide from Massive Rock Slope Failure. NATO Science Series IV: Earth and Environmental Sciences, vol. 49, pp. 211-232.

Cruden, D.M., Varnes, D.J., 1996. Landslide types and processes. In: Turner, A.K., Schuster, R.L. (Eds.), Landslides Investigation and Mitigation. National Research Council, Transportation Research Board, Washington, DC, pp. 36-75.

Cundall, P.A., 1971. A computer model for simulating progressive large scale movement in blocky rock systems. Proceedings of the Symposium of the International society of rock mechanics, vol. 1. Nancy, France, pp. II-8.

Cundall, P.A., Strack, P.D.L., 1979. A discrete numerical model for granular assemblies. Géotechnique 29, 47-65.

Denlinger, R.P., Iverson, R.M., 2001. Flow of variably fluidized masses across threedimensional terrain: 2. Numerical predictions and experimental tests. Journal of Geophysical Research 106 (B1), 553-566.

Eriscmann, T.H., 1986. Flowing, rolling, bouncing, sliding: synopsis of basic mechanisms. Acta Mechanica 64, 101-110.

Erismann, T.-H., 1979. Mechanisms of large landslides. Rock Mechanics 12, 15-46.

Fakhimi, A., 2004. Application of slightly overlapped circular particles assembly in numerical simulation of rocks with high friction angles. Engineering Geology 74 129-138.

Fakhimi, A., Villegas, T., 2007. Application of dmensional anlysis in calibration of a discrete element model for rock deformation and fracture. Rock Mechanics and Rock Engineering 40, 193-211.

Forlati, F., Gioda, G., Scavia, C., 2001. Finite element analysis of a deep-seated slope deformation. Rock Mechanics and Rock Engineering 34 (2), 135-159.

Habib, P., 1967. Sur un mode de glissement des massifs rocheux. Comptes Rendus de l' Académie des Sciences, Paris, 264, 151-153.

Habib, P., 1975. Production of gaseous pore pressure during rock slides. Rock Mechanics 193-197.

Heim, A., 1932. Bergsturz und Menschenleben. Fretz and Wasmuth, Zürich. 218 pp.

Howard, K.E., 1973. Avalanche mode of motion: implications from lunar example. Science $180,1052-1055$.

Hsü, K.J., 1975. Catastrophic debris streams (sturzstroms) generated by rockfalls. Geological Society of America Bulletin 86,129-140.

Hsü, K.J., 1978. Albert Heim: observations on landslides. In: Voight, B. (Ed.), Rockslides and Avalanches, vol. 1. Elsevier, Amsterdam, pp. 70-93.

Hsu, T.-L., Leung, H.-P., 1977. Mass movements in the Tsaoling area, Yunlin-Hsien, Taiwan. Proceedings of the Geological Society of China 20, 114-118.

Huang, C.-S., Ho, H.-C., Liu, H.-C., 1983. The geology and landslide of Tsaoling area, Yunlin, Taiwan. Bulletin of the Central Geological Survey 2, 95-112.

Huang, C.-C., Lee, Y.-H., Liu, H.-P., Keefer, D.K., Jibson, R.W., 2001. Influence of surfacenormal ground acceleration on the initiation of the Jih-Feng-Erh-Shan landslide during the 1999 Chi-Chi, Taiwan, Earthquake. Bulletin of Seismicity of the Socia America 91, 953-958.

Hung, J.-J., 2000. Chi-Chi earthquake induced landslides in Taiwan. Earthquake Engineering and Engineering Seismology 2, 25-32.

Hung, J.-J., Lee, C.-T., Lin, M.-L., 2002. Tsao-Ling rockslides, Taiwan, catastrophic landslides: effects, occurrence, and mechanisms. Geological Society of America Reviews in Engineering Geology 15, 91-115.

Hutter, K., Koch, T., Pluss, C., Savage, S.B., 1995. The dynamics of avalanches of granular materials from initiation to runout, Part II, Experiments. Acta Mechanica 109,127-165.

Itasca, Consulting Group Inc., 2002. PFC2D Particle Flow Code in 2 Dimensions. User's Guide. Minneapolis.

Iverson, R.M., Denlinger, R.P., 2001. Flow of variably fluidized masses across threedimensional terrain: 1. Coulomb mixture theory. Journal of Geophysical Research 106 (B1), 537-552.

Iverson, R.M., Vallance, J.W., 2001. New views of granular mass flow. Geology 29 (2), 115-118.

Johnson, B., 1979. In: Voight, B. (Ed.), Blackhawk Lanslide in California. U.S.A., Rockslides and Avalanches, vol. 1, pp. 481-504.

Kao, H., Chen, W.-P., 2000. The Chichi earthquake sequence: active out-of-sequence thrust faulting in Taiwan. Science 30, 2346-2349.
Keefer, D.K., 1984. Landslides caused by earthquakes. Geological Society of America Bulletin 95, 406-421.

Keefer, D.K., 2000. Statistical analysis of an earthquake-induced landslide distribution: the 1989 Loma Prieta, California event. Engineering Geology 58, 231-249.

Keefer, D.K., Larsen, M., 2007. Assessing landslide hazards. Science 316, 1136-1138.

Kent, P.E., 1966. The transport mechanism in catastrophic rockfalls. Journal of Geology 74, 79-83.

Lee, C.-N., 2001. Preliminary study on the Tsao-Ling landslide area under earthquake. Master Thesis, Department of Civil Engineering, National Taiwan University, Taipei.

Lee, C.-T., Hung, J.-J., Lin, M.-L., Tsai Louis Loung-Yie, 1993. Engineering Geology Investigations and Stability Assessments on Tsao-Ling Landslide Area: a Special Report Prepared for Sinotech Engineering Consultants. 224 pp (in Chinese).

Lee, J.-C., Chu, H.-T., Angelier, J., Chan, Y.-C., Hu, J.-C., Lu, C.-Y., Rau, R.-J., 2002. Geometry and structure of northern surface rupture of the $1999 \mathrm{Mw}=7.6$ Chi-Chi, Taiwan Earthquake: influence from inherited Fold Belt structures. Journal of Structural Geology 24, 173-192.

Legros, F., 2002. The mobility of long-runout landslides. Engineering Geology 63 301-331.

Liao, H.-W., 2000, Landslides triggered by Chi-Chi earthquake. Master Thesis, Institute of Geophysics, National Central University, Chung-Li, 90 p.

Lucchitta, B.K., 1978. Valles Marineris, Mars: Wet Debris Flows and Ground Ice. U.S Geological Survey, 2255 North Gemini Drive, Flagstaff, Arizona 86001, USA Received 12 January 1987; revised 19 May 1987. Available online 14 October 2002.

Lucchitta, B.K., 1979. Landslides in Valles Marineris, Mars. Journal of Geophysical Research 84, 8097-8113.

McDowell, G.R., Harireche, O., 2002. Discrete element modeling of soil particle fracture. Géotechnique 52, 131-135.

McEwen, A.S., 1989. Mobility of large rock avalanches: evidence from Valles Marineris, Mars. Geology 17 (12), 1111-1114.

Melosh, H.J., 1979. Acoustic fluidization: a new geological process? Journal of Geophysical Research 84, 7513-7520.

Melosh, H.-J., 1986. The physics of very large landslides. Acta Mechanica 64, 89-99.

Muller, L., 1964. The rock slide in the Vaiont valley. Felsmechanik und Ingenieurgeologie 2, 148-212.

Newmark, N.M., 1965. Effects of earthquake on dams and embankments. Géotechnique $15,139-160$

Poisel, R., Roth, W., 2004. Runout models of rock slope failures. Felsbau 22, 46-50.

Potyondy, D., Cundall, P., 2001. The PFC Model for Rock: Predicting Rock Mass Damage at the Underground Research Laboratory, Report no. 06819-REP-01200-10061-R00. Itasca Consulting Group, MN, USA.

Potyondy, D.O., Cundall, P.A., 2004. A bonded-particle model for rock. International Journal of Rock Mechanics and Mining Sciences 41, 1239-1364.

Preh, A., Poisel, R., 2007. 3D modelling of rock mass falls using the Particle Flow Code PFC3D. Proc. 11th Congr. ISRM, Lissabon 2007. Specialized Session S01 - Rockfall Mechanism and Hazard Assessment.

Quantin, C., Allemand, P., Delacourt, C., 2004. Morphology and geometry of Valles Marineris landslides. Planetary and Space Science 52, 1011-1022.

Quecedo, M., Pastor, M., Herreros, M.I., Fernández Merodo, J.A., 2004. Numerica modelling of the propagation of fast landslides using the finite element method. International Journal for Numerical Methods in Engineering 59, 755-794.

Seed, H.B., 1979. Consideration in the earthquake-resistant design of earth and rockfil dams. Géotechnique 29, 215-263.

Shreve, R.L., 1968. The Blackhawk landslide. Special Paper, Geological Society of America Bulletin, vol. 108. 47 pp.

Skemption, A.W., 1966. Bedding-plane slip, residual strength and the Vaiont Landslide. Géotechnique 16, 82-84.

Soukhovitskaya, V., Manga, M., 2006. Martian landslide in Valles Marineris: wet or dry? Icarus $180,348-352$

Sousa, J., Voight, B., 1991. Continuum simulation of flow failures. Geotechnique 41 515-538.

Taboada, A., Chang, K.-J., Radjaï, F., Bouchette, F., 2005. Rheology, force transmission, and shear instabilities in frictional granular media from biaxial numerical tests using the contact dynamics method. Journal of Geophysical Research 110, B09202. doi:10.1029/2003JB002955.

Taboada, A., Estrada, N., Radjaï, F., 2006. Additive decomposition of shear strength in cohesive granular media form grain-scale interactions. Physical Review Letters 97, 098302. doi:10.1103/PhysRevLett.97.098302.

Taiwan Provincial Water Conservancy Bureau, 1979. Tsaoling Landslide Archives, Taiwan, ROC. (in Chinese).

Tsai, Y.-B., 1985. A study of disastrous earthquakes in Taiwan, 1683-1895. Bulletin of the Institute Earth Sciences, Academia Sinica 5, 1-44.

Vardoulakis, I., 2002. Dynamic thermo-poro-mechanical analysis of catastrophic landslides. Géotechnique 52 (3), 157-171.

Voight, B., Faust, C., 1982. Frictional heat and strength loss in some rapid landslides. Géotechnique 32 (1), 43-54.

Wieczorek, G.F., Willson, R.C., Harp, E.L., 1982. Map showing slope stability during earthquakes in San Mateo Country, California, U.S. Geology Survey Miscellaneous Investigation Series Map, Map I-1257E.

Wilson, R.C., Keefer, D.K., 1983. Dynamics analysis of a slope failure from the 6 August 1979 Coyote Lake, California, Earthquake. Bulletin of Seismicity of the Socia America 65, 1239-1257.

Yang, M., Rau, R.-J., Yu, J.-Y., Yu, T.-T., 2000. Geodetically observed surface displacements of the 1999 Chi-Chi, Taiwan, Earthquake. Earth Planets Space 52, 403-413.

Yeng, K.-T., 2000. The residual strength of Chin-Shui shale in relation to the slop stability of Tsao-Ling. Mater Thesis, Department of Civil Engineering, National Taiwan University, Taipei. 
Yoon, J., 2007. Application of experimental design and optimization to PFC model calibration in uniaxial compression simulation. International Journal of Rock mechanics \& Mining Sciences 44, 871-889.

Yu, S.-B., Kuo, L.-C., Hsu, Y.-J., Su, H.-H., Liu, C.-C., Hou, C.-S., Lee, J.-F., Lai, T.-C., Liu, C.-C., Liu, C.-L., Tseng, T.-F., Tsai, C.-S., Shin, T.-C., 2001. Preseismic deformation and coseismic displacements associated with the 1999 Chi-Chi, Taiwan Earthquake. Bulletin of Seismicity of the Social America 91, 995-1012.

Zheng, H., Liu, D.F., Li, C.G., 2005. Slope stability analysis based on elasto-plastic finite element method. International Journal for Numerical Methods in Engineering 64, 1871-1888. 